\title{
Optimal Fiscal Strategy for Oil Exporting Countries
}

\author{
EduARdo Engel ANd Rodrigo VALdÉs ${ }^{1}$
}

January 27,2000

\begin{abstract}
This paper develops simple guidelines for fiscal policy in oil producing countries, focusing on three issues: intergenerational oil distribution, precautionary saving, and adjustment costs. The paper presents a framework to analyze how the revenue generated by an exhaustible source of wealth that belongs to the government should be distributed between current and future generations. This framework is used to show the strengths and limitations of existing answers, which motivates a new approach for dealing with this question. The paper derives simple, closed form approximations to the optimal level of government expenditure when an important part of government revenue is generated by an uncertain and exhaustible natural resource such as oil. Price uncertainty, budget uncertainty, and the (possibly asymmetric) costs of adjusting expenditure levels are considered.
\end{abstract}

Key words: optimal fiscal policy, stabilization fund, intergenerational oil distribution, precautionary saving, adjustment costs, exhaustible natural resources, optimal government expenditure, price uncertainty, budget uncertainty, oil exporting countries

JEL classification: E21, E61, E62, H50, H60, O16, O23, O53, Q33, Q38

\footnotetext{
${ }^{1}$ Engel: Center for Applied Economics (CEA), Department of Industrial Engineering, University of Chile and NBER. Valdés: Central Bank of Chile. E-mail: eengel@dii.uchile.cl and rvaldes@minhda.cl. This paper was prepared for the Middle Eastern Department at the International Monetary Fund. The authors thank David Burton, Paul Chabrier, Ugo Fasano, Antonio Rangel and seminar participants at the IMF for helpful comments and suggestions. All remaining errors are our responsibility. This paper presents the views of the authors and does not represent in any way positions or views of the Central Bank of Chile.
} 


\section{Contents}

1 Introduction $\quad 3$

2 Framework $\quad 4$

2.1 Social Welfare Function . . . . . . . . . . . . . . . . . . . . 5

2.1 .1 Instantaneous Utility Function $\ldots \ldots \ldots \ldots$

2.1 .2 Social Welfare Functions . . . . . . . . . . . . . . . . 6

2.1.3 Incorporating Adjustment Costs . . . . . . . . . . . . . . 7

2.2 Policy Instruments . . . . . . . . . . . . . . . . . . . . . . . . . . 8

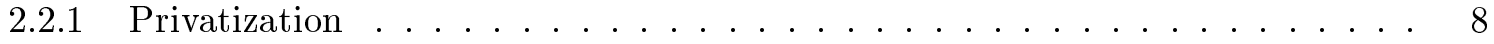

2.2 .2 Savings . . . . . . . . . . . . . . . . . . 8

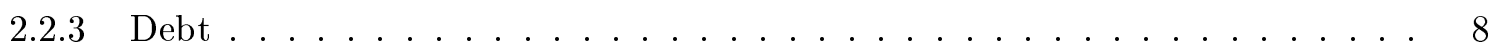

2.2.4 Taxes and Transfers . . . . . . . . . . . . . . . . . . . . 9

2.2.5 Government Expenditures . . . . . . . . . . . . . . . . . 9 9

2.2.6 Stabilization Funds . . . . . . . . . . . . . . . . . . . . 10

2.3 Private Sector . . . . . . . . . . . . . . . . . . . . . 10

3 Intuitions $\quad 11$

3.1 Consumption Smoothing . . . . . . . . . . . . . . . . . . . . 11

3.2 Precautionary Saving . . . . . . . . . . . . . . . . . . . . . . 12

3.3 Adjustment Costs . . . . . . . . . . . . . . . . . . . . 13

3.4 Separability of the Investment Problem . . . . . . . . . . . . . . . . . 13

3.5 Tax Smoothing . . . . . . . . . . . . . . . . . . . . . 13

4 Intergenerational Redistribution $\quad 14$

4.1 Benchmark Model . . . . . . . . . . . . . . . . . . . . . . . . . . . 14

4.1 .1 Examples . . . . . . . . . . . . . . . . . . . . 16

4.1 .2 Incorporating a Bequest Motive . . . . . . . . . . . . . . . 17

4.2 Permanent Oil Income Model . . . . . . . . . . . . . . . . . . . . . . . . . 17

4.2 .1 Examples . . . . . . . . . . . . . . . . . . . . 19

4.3 A New Approach . . . . . . . . . . . . . . . . . . . . . 20

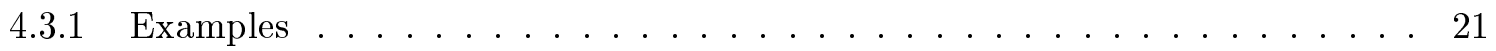

5 Oil Related Uncertainty 22

5.1 Previous Literature . . . . . . . . . . . . . . . . . . . . 23

5.2 Revisiting the Random Walk Hypothesis . . . . . . . . . . . . . . . 25

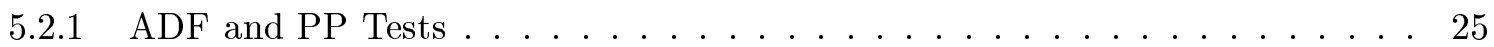


5.2 .2 Variance Ratio Test . . . . . . . . . . . . . . . . . 26

5.2 .3 Non-linear Adjustment . . . . . . . . . . . . . . . . . . . . . . . . . . . . . . . . .

5.3 Evaluation of Alternative Models . . . . . . . . . . . . . . . 27

6 Precautionary Saving and Adjustment Costs 29

6.1 Income and Budget Uncertainty . . . . . . . . . . . . . . . . 30

6.1 .1 Correction Factors . . . . . . . . . . . . . . . . . . . 31

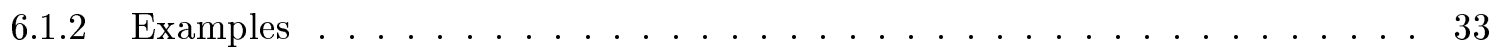

6.2 Adjustment Costs . . . . . . . . . . . . . . . . . 35

6.2.1 Quadratic Adjustment Costs . . . . . . . . . . . . . . 35

6.2.2 Eliciting Adjustment Costs . . . . . . . . . . . . . . . 36

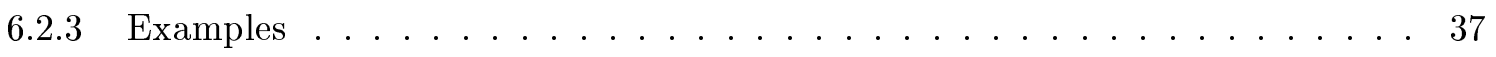

$\begin{array}{lll}7 & \text { Stabilization Funds } & \mathbf{3 7}\end{array}$

8 Concluding Remarks $\quad 39$

A Benchmark and Conditionally Normative Models 43

$\begin{array}{ll}\text { B Precautionary saving } & 46\end{array}$

$\begin{array}{ll}\text { C Adjustment Costs } & 52\end{array}$ 


\section{Introduction}

Conducting appropriate fiscal policy may be particularly difficult when a large share of government revenue comes selling a government owned exhaustible natural resources such as oil. Large and unpredictable fluctuations in international oil prices may make the determination of appropriate expenditure levels particularly difficult. In addition, since oil wealth is exhaustible, intergenerational equity considerations must also be taken into account. This is the case of the oil exporting countries where most of the government's revenue comes from oil and gas production.

This paper develops guidelines for fiscal policy in countries where the government owns an uncertain and exhaustible income stream. Figuring out optimal fiscal policy is a complex exercise that usually requires the use of numerical simulations and solutions - a black box from a policymaking perspective with slim chances of actually being applied. In this paper we provide explicit, closed approximations to the optimal solution of an otherwise standard problem. Our objective is to derive a set of simple and intuitive rules that can be easily applied by policymakers.

We focus on three different issues. First, we study the problem of intergenerational distribution of state-owned exhaustible resources. For that purpose we present a framework in which the problem can be analyzed and evaluate the strengths and limitations of existing answers. We then propose a new approach to tackle the issue.

Second, we study the need for savings due to the uncertain nature of future income, what is known as precautionary saving. We consider the impact of two sources of uncertainty on optimal consumption, namely future income uncertainty and uncertainty about income during the budget year under consideration. We propose correction factors to be applied to the certainty equivalence solution that leave consumption close to the optimal level.

Third, we study the process of expenditure adjustment in presence of (asymmetric) quadratic adjustment costs. Given adjustment costs we derive the speed at which adjustments should be made. We also provide guidelines to help elicit from policymakers the size of adjustment costs.

The policy guidelines derived in this paper often call for important savings in the near future, both due to intergenerational considerations, since wealth is front loaded, and because of precautionary saving. One way of implementing these guidelines is establishing a stabilization fund. This paper discusses how the results we develop can be used to implement a such a fund. ${ }^{2}$

Policy prescriptions for optimal government expenditure may vary considerably with the stochastic process assumed for the price of oil. For this reason this paper undertakes a detailed evaluation of the quality of out-of-sample forecasts of a large number of time series models that have been proposed for commodity prices. We find that most models perform substantially worse

\footnotetext{
${ }^{2}$ A detailed discussion of this topic would constitute another paper altogether. For this reason we concentrates on how a stabilization fund can be used to implement optimal fiscal policy prescriptions.
} 
and none significantly better than a geometric random walk where the forecast of future prices is equal to the current price.

This paper studies fiscal strategy from a normative point of view. Our purpose is to develop a set of rules that can improve welfare assuming a particular set-up. The paper does not study problems of fiscal policy sustainability, ${ }^{3}$ since we assume throughout that the government intertemporal budget constraint is always satisfied, thereby ruling out Ponzi schemes.

The paper is organized as follows. Section 2 presents a framework to discuss the intergenerational oil distribution problem. Section 3 discusses the intuitions behind the design of optimal fiscal policy. Section 4 evaluates two existing approaches to the problem of intergenerational distribution and proposes a new one. Section 5 characterizes the stochastic process of oil prices. Section 6 derives policy guidelines based on precautionary saving and adjustment costs. Section 7 discusses the role of stabilization funds. Finally, section 8 concludes.

\section{$2 \quad$ Framework}

In this section we provide an organizing framework to analyze the following question:

How should the revenue generated by an uncertain source of wealth that belongs to the government, such as oil in the case of oil exporting countries, be spent and distributed between current and future generations?

An answer to this question has important policy implications, since it brings with it a prescription for optimal fiscal policy, providing guidelines for managing variables such as government deficits, government expenditures, taxes, the current account and stabilization funds.

The standard economic framework for analyzing the normative question we are concerned with is the following one:

(a) Choose a Social Welfare Function (SWF).

(b) Decide the set of policy instruments available to the government and the constraints it faces.

(c) Choose a set of assumptions (and constraints) for private sector behavior.

(d) Find the values of the policy instruments considered in (b) that maximize the SWF specified in (a) subject to the behavioral assumptions made in (c). We refer to this problem as the Optimal Consumption Problem.

\footnotetext{
${ }^{3}$ See., e.g., Liuksila et al. (1994) for a discussion about fiscal sustainability in oil producing countries.
} 
The SWF we select, the policy instruments we consider and the behavioral assumptions we make will determine the optimal consumption path and, in doing so, the optimal fiscal policy. Next we discuss each of these choices in detail.

\subsection{Social Welfare Function}

Typically a SWF is a function of the instantaneous utility of consumption of current and future generations. When specifying a SWF we specify the relative importance of current and future consumption, and the consumption goods considered in the instantaneous utility. In doing so we set a key ingredient to determine both how much future generations benefit from oil wealth and how much redistribution of private wealth across generations takes place.

\subsubsection{Instantaneous Utility Function}

This function, also called felicity function, measures the utility derived from consumption during a given time period.

We assume that there are two separate consumption goods, one provided by the government and another by the private sector. We refer to the consumption good provided by the government as publicly provided good, or public good for short, even though for the questions at hand we do not need to emphasize the fact that many of these goods are, to some extent, non rival in consumption. What matters in our setting is that it has to be provided by the government, thereby providing a rationale for taxation.

Denoting per capita consumption of these goods by $c_{G}$ and $c_{P}$ we have that the instantaneous utility function, $u$, is of the form:

$$
u=u\left(c_{G}, c_{P}\right)
$$

The function $u$ is increasing in both $c_{G}$ and $c_{P}$, with decreasing marginal utility. Also, both goods are complements in consumption, that is, the marginal utility of consuming the private good increases with the level of consumption of the public good.

A standard functional form for $u$ is the Constant Elasticity of Substitution (CES) utility function:

$$
u\left(c_{G}, c_{P}\right)=\left[\frac{c_{G}^{1-\gamma}}{1-\gamma}+k \frac{c_{P}^{1-\gamma}}{1-\gamma}\right]^{1 /(1-\gamma)} .
$$

Where $k \geq 0$ and $\gamma>0 .{ }^{4}$ The parameters $k$ measures the relative importance of both consumption goods, while $1 / \gamma$ captures the elasticity of substitution between both goods.

\footnotetext{
${ }^{4}$ For $\gamma=1$ we may define, by continuity, $u\left(c_{G}, c_{P}\right)=\log \left(c_{G}\right)+k \log \left(c_{P}\right)$.
} 
For simplicity we assume that $c_{G}$ is determined by the government's current expenditure level. A more realistic assumption, which we may explore in future versions of this paper, is that it also depends on past government expenditures. ${ }^{5}$

\subsubsection{Social Welfare Functions}

A typical SWF (at time 0) is (the expected value of) a function of the instantaneous utilities of present and future generations:

$$
\mathcal{W}=\mathrm{E}_{0}\left[W\left(u_{0}, u_{1}, u_{2}, \ldots\right)\right]
$$

Where $\mathrm{E}_{0}$ denotes the expected value, conditional on the distributions of unknown quantities (such as future oil prices) based on information available at time $t=0$ and $u_{0}, u_{1}, u_{2}, \ldots$ denote the instantaneous utilities at times $0,1,2, \ldots$ The function $W$ is increasing in all its arguments. It also exhibits decreasing marginal returns in all its arguments.

The quantities $u_{0}, u_{1}, u_{2}, \ldots$ in (3) may also be interpreted as the utilities of a representative consumer in consecutive years (instead of generations).

The most commonly used SWF are the following:

\section{Utilitarian SWF}

A SWF $W$ is utilitarian (or of the Bentham-Ramsey type) if it is a weighted sum of the utility of present and future generations:

$$
W\left(u_{0}, u_{1}, u_{2}, \ldots\right)=\sum_{t \geq 0} \beta^{t} N_{t} H\left(u_{t}\right) .
$$

The parameter $\beta$ denotes the subjective discount rate. This value is close to but smaller than one; the smaller it is, the larger the degree of impatience in the SWF.

$N_{t}$ denotes the population at time $t$. The social welfare function grows in proportion to the population. We will assume that $N_{t}=(1+n)^{t}$, so that the population grows at a constant rate $n$.

The function $H$ is a standard utility function, increasing, with decreasing marginal utility. A particularly useful case of (4) is:

$$
H(u)=u^{1-\rho} /(1-\rho),
$$

with $\rho>0 .{ }^{6}$ This is the Constant Elasticity of Substitution (CES) utility function: $1 / \rho$ denotes the elasticity of substitution of consumption at different moments in time. Furthermore, if there is

\footnotetext{
${ }^{5}$ This requires distinguishing between government expenditures on the public good and government investments that produce a future flow of the public good.

${ }^{6}$ If $\rho=1$ we define $H(u)=\log (u)$.
} 
uncertainty about future incomes, $\rho$ is the coefficient of relative risk aversion (CRRA).

\section{Rawlsian SWF}

In this case the social welfare function to be maximized is the (expected value of the) utility of the generation with smallest utility:

$$
W\left(u_{0}, u_{1}, u_{2}, \ldots\right)=\mathrm{E}\left[\min \left(u_{0}, u_{1}, u_{2}, \ldots\right)\right]
$$

\subsubsection{Incorporating Adjustment Costs}

Changes in government expenditures may have consequences that are not captured by the Social Welfare Functions described above. A drastic reduction in government expenditures may lead to political instability, discouraging investment and reducing future growth. A sudden increase in government expenditures may increase the likelihood of having badly managed government projects because of the lack of adequate supervision. It may also increase the costs of projects because of bottlenecks in the supply of certain inputs.

The SWFs described so far can be extended to capture the effect mentioned above by adding an adjustment cost to the instantaneous utility in equation (4):

$$
W\left(u_{0}, u_{1}, u_{2}, \ldots\right)=\sum_{t \geq 0} \beta^{t} N_{t}\left[H\left(u_{t}\right)-A\left(c_{G, t}, c_{G, t-1}\right)\right] .
$$

Where $A\left(c_{G, t}, c_{G, t-1}\right)$ captures the costs of adjusting per capita government expenditures from $c_{G, t-1}$ to $c_{G, t}$.

Some possible functional forms for $A$ are the following:

$$
\begin{aligned}
& A\left(c_{G, t}, c_{G, t-1}\right)=k\left(c_{G, t}-c_{G, t-1}\right)^{2}, \\
& A\left(c_{G, t}, c_{G, t-1}\right)=k\left(\log \left(c_{G, t}\right)-\log \left(c_{G, t-1}\right)\right)^{2}, \\
& A\left(c_{G, t}, c_{G, t-1}\right)=k \max \left(0, c_{G, t-1}-c_{G, t}\right) .
\end{aligned}
$$

Both (8) and (9) correspond to quadratic adjustment costs, while (10) describes the case where only reductions in per capita government expenditures are costly. In all cases the parameter $k$ determines the magnitude of adjustment costs.

The examples given above assume that adjusting the consumption of the public good is costly. If adjusting per capita levels of consumption of the private good is also costly, the adjustment cost functions should depend on total per capita consumption. 


\subsection{Policy Instruments}

A variety of policy instruments may be available to governments when implementing fiscal policies. Savings and debt, taxation, investment, and stabilization funds are among those most relevant for the problem considered in this paper.

\subsubsection{Privatization}

The government of an oil exporting country could consider the possibility of privatizing the stateowned oil monopoly, as was done, for example, recently in Argentina. ${ }^{7}$ In this paper we rule out this possibility. One reason for doing so is that the government may be unable to commit credibly not to expropriate the privatized firm. Yet even if oil is fully privatized, the fiscal authority still faces the problem of how to distribute the proceeds across generations. What privatization does is reduce uncertainty with respect to initial wealth, besides likely efficiency gains which go beyond the scope of this paper.

Even though we do not consider privatization in the set of feasible policy instruments, we extensively use the possibility of future privatization as a convenient short-cut to derive approximations to the solution of the optimal consumption problem under uncertainty.

\subsubsection{Savings}

Governments can hold financial assets to finance future expenditures. We denote the gross real interest rate accrued per period for these savings by $R$, and assume that it is known and constant over time.

\subsubsection{Debt}

Governments incur debt to finance current consumption, investment and interest payments on previously incurred debt. The interest paid varies over time, both due to international and local factors. Nonetheless, interesting insights can be obtained even if the simplifying assumption of a fixed real interest is made. This assumption is justified by noting that oil prices are considerably more volatile than interest rates. Furthermore, we ignore any difference between the interest rate paid on debt and that accrued to savings, and denote both gross rates by $R$.

The following equation describes the evolution of government financial assets, when savings and debt at a gross interest rate of $R$ are possible:

$$
F_{G, t+1}=R\left(F_{G, t}+Y_{G, t}-C_{G, t}\right) .
$$

\footnotetext{
${ }^{7}$ It should be noted, though, that oil is not one of Argentina's main exports.
} 
Where $F_{G, t}$ denotes government financial assets accumulated at the beginning of period $t, Y_{G, t}$ denotes government income during period $t$ (assumed to accrue at the beginning of the period), and $C_{G, t}$ denotes government expenditures during period $t$, which are equal to private consumption of the public good, and which are also assumed to be made at the beginning of the period.

There typically is a limit to government debt, say as a fraction of GDP. This limit may vary over time, responding both to local and international factors. A closely related constraint which is often mentioned is an upper limit on the current account deficit, also as a fraction of GDP.

\subsubsection{Taxes and Transfers}

The government may collect taxes and may also transfer assets to its citizens.

Taxes can be used to finance the current production of public goods, current public investments and interest payments on government debt. For a given level of current expenditures on consumption goods, the government should raise taxes (or give transfers) that help achieve the optimal mix of the public and private consumption good. For example, if in a given year the government's income is very high compared with the private sector's income, as could be the case for a country rich in government owned natural resources, a government transfer to the private sector may be needed to provide the appropriate mix of public and private consumption goods. ${ }^{8}$

Another reason for raising taxes is to transfer income across generations (intergenerational transfers). If future generations are expected to be much better off than the current generation, a society may wish to subsidize current consumption by borrowing against taxes that will be paid by future generations.

Taxes may also be used to improve the distribution of income within a generation. Since all the models considered in this paper have one agent representing each generation, this motive will not be considered.

Denoting taxes raised in period $t$ by $\Gamma_{t}$, and interpreting transfers as negative taxes, we have that (11) generalizes to:

$$
F_{G, t+1}=R\left(F_{G, t}+Y_{G, t}+\Gamma_{t}-C_{G, t}\right) .
$$

\subsubsection{Government Expenditures}

The government spends money to produce the public good and to finance investments that will enable future production of the public good. Here the "public good" can be interpreted, among other things, as education, health and defense.

\footnotetext{
${ }^{8}$ Such transfers do happen in practice, for example, by extending the scope for government expenditures. Of course, this is not necessarily efficient.
} 
Government expenditures face an intertemporal budget constraint, that is they must eventually be financed through taxes or other sources of government income. This budget constraint, as of period 0 , states that the present value of government incomes must equal the present value of government expenditures, that is:

$$
F_{G, 0}+\sum_{t \geq 0} R^{-t}\left[Y_{G, t}+\Gamma_{t}\right]=\sum_{t \geq 0} R^{-t} C_{G, t}
$$

\subsubsection{Stabilization Funds}

A stabilization fund saves and spends money with the objective of stabilizing a specific aggregate variable, such as overall government expenditures or government expenditures financed from the profits generated by a government owned primary commodity such as oil. The fund is held in liquid assets and incentives must be put in place to prevent the assets from being spent due to political pressures.

A well designed stabilization fund should be closely related to the solution of a problem of the sort posed at the beginning of this section. The savings/spending rule should be such that, in combination with other sources of government savings/credit, it implements the optimal fiscal strategy. Furthermore, a government may value liquidity per se, in which case having a stabilization fund may be desirable even if the government's net financial position is negative.

\subsection{Private Sector}

An important issue regarding private sector behavior is whether there is a bequest motive or not. The assumption of no bequest motive (or, more generally, of a weak bequest motive) is implicit in the intergenerational equity question central to this paper, for otherwise no government intervention would be needed to ensure that future generations benefit government owned wealth. If current generations do not care for their descendants, the private sector will not save for future generations and, given the opportunity to do so, will spend all the government owned wealth. ${ }^{9}$

The private sector also participates in the production of goods and services in markets which are assumed competitive. These goods and services may be consumed locally or exported. The private sector also has access to international finance for investment projects within the country.

The private sector also maximizes a welfare function, which even though qualitatively similar to the SWFs considered earlier in this section, may differ in some fundamental ways. An important difference we will encounter in most cases is that the time horizon considered by private agents is considerably shorter than that considered by the government's SWF. This is due to our assumption that private agents do not want to leave inheritance to their descendants.

\footnotetext{
${ }^{9}$ Strictly speaking this assumes no uncertainty about an individuals life span. If individuals do not know when they will die, they may die with positive net assets but this effect is typically small and will be neglected.
} 
We will see in Section 4 that the interaction between the objectives posed by the government's SWF and the private sector's behavior may lead to surprising results. For example, if it wishes, the government may use fiscal policy to have the currently alive private sector care for future generations.

\section{Intuitions}

In this section we describe some simple intuitions underlying policy prescriptions for fiscal policy. As discussed in Section 4, these intuitions often follow from particular cases of the framework presented in Section 2.

\subsection{Consumption Smoothing}

Individuals dislike variations in consumption and are generally willing to sacrifice some welfare to avoid such fluctuations. For this reason, in the absence of income uncertainty, optimal fiscal policy often requires that per capita consumption levels remain constant over time. With income uncertainty this intuition needs to be modified, and current consumption levels are equal to permanent income, so that, in expectations or on average consumption is constant over time (Friedman [1957]).

For example, after discovering a new exhaustible natural resources, say natural gas in Qatar, consumption should increase by the annuity value of the corresponding increase in wealth. The country acts as if it deposited in a bank abroad the present discounted value of the profits it expects to make from selling the natural resource, and spends every year the interest payments it receives. Consumption should increase immediately after the natural gas is discovered, if the country can borrow against future incomes there is no reason to wait until production begins. Thus the current account deteriorates immediately after the discovery of natural gas and recuperates once actual production begins.

As we shall see in Section 4, the main assumption underlying consumption smoothing in the case without income uncertainty is that $\beta R=1$, where we recall that $\beta$ denotes the subjective discount rate and $R$ the gross interest rate. Even though it may be argued that in the long run $\beta R$ will be close to one, in the short and medium run (e.g., over the next couple of decades) there is no reason why this should be the case. If $\beta R<1$, which may be interpreted as society being relatively impatient, per capita consumption falls over time at a constant rate. Alternatively, if $\beta R>1$, per capita consumption grows at a constant rate.

The extension of the consumption smoothing intuition to the case with uncertain incomecertainty equivalence - assumes that the instantaneous utility function is quadratic. This assumption is popular precisely because it preserves this intuition, even though it has some unappealing 
properties, such as a degree of risk aversion that increases with consumption levels and the implication that the optimal consumption path does not depend on the variance of income.

Another intuition that follows from consumption smoothing with uncertain income is that the government should react differently to transitory and permanent changes in income. A transitory positive shock to income should increase consumption only by the annuity value of the income shock. By contrast, a permanent increase should be met by a one-for-one reduction of consumption. For example, the increase in the price of oil following the invasion of Kuwait by Iraq in August of 1990 was clearly transitory. By the time the oil price had returned to its pre-invasion levels (in mid 1991), the rule described above can be used to spend the windfall generated by the price increase.

More generally, if income follows an autoregressive process with first order correlation $\psi$, which therefore also captures the degree of persistence of income shocks, the fraction of the current shock to income that should be spent is $(R-1) /(R-\psi) .{ }^{10}$ The case $\psi=0$ corresponds to i.i.d. (and therefore transitory) shocks while $\psi=1$ corresponds to the case where income follows a random walk (permanent shocks).

In practice it is often not easy to determine the extent to which a change in income is permanent or transitory. Most shocks can be thought of as having both a permanent and a transitory component. In Section 6 we review recent econometric developments that can be used to accomplish this decomposition, concluding that a geometric random walk appears as a sensible description for the oil price.

Furthermore, because oil is an exhaustible resource, even permanent price shocks have only a transitory effect on income. The transitory component of the shock is more important the shorter the expected duration of the resource.

\subsection{Precautionary Saving}

A fundamental intuition underlying savings behavior is that an increase in risk should increase current savings and decrease current consumption. This is known as the precautionary saving motive, see Leland (1968). The consumption smoothing intuition does not incorporate this idea, since it prescribes that the current annuity value of expected wealth should be spent every year, regardless of the degree of uncertainty associated with this wealth.

To capture the precautionary savings motive, we must consider more realistic instantaneous utility functions than the quadratic case. This typically comes at the price of not having an explicit expressions for optimal consumption, ${ }^{11}$ and numerical methods must be used to determine the optimal plan (as in Zeldes [1989], Deaton [1991] and Carroll [1992]).

\footnotetext{
${ }^{10}$ See, for example, Flavin (1981).

${ }^{11}$ Caballero (1990) finds a particular case where an explicit expression for optimal consumption can be derived. Yet he assumes constant absolute risk aversion, which also has unappealing properties.
} 
¿From a policy perspective, these numerical procedures have limited applicability. Implementing solutions is cumbersome and the results are not as transparent as the political process requires. In this paper we derive approximations to the optimal consumption plan that are closed-form and can be easily interpreted. Their simplicity should be a great advantage in terms of applicability.

We consider two sources of uncertainty: the usual income uncertainty and what we call budget uncertainty, which attempts to capture the uncertainty that governments face when designing next year's budget. In particular, we consider the effect of not knowing the income level that will prevail during the coming year. This type of uncertainty is different from the one that originates the standard precautionary savings because it focuses on the level of prices only one period ahead. ${ }^{12}$

\subsection{Adjustment Costs}

In the presence of adjustment costs as those described in section 2.1.3 (convex adjustment costs) governments typically adjust their per capita expenditures slower than they would in the absence of such costs. For example, following the discovery of gas reserves, the government should increase its spending on the public good only slowly until it achieves its new and, in the absence of income fluctuations, constant level. The larger the adjustment costs, the slower the process by which consumption increases and the higher the steady state level of consumption.

Below we derive a closed-form solution for a partial adjustment model in which the adjustment coefficient is a function of the size of the adjustment cost (that could be asymmetric). Moreover, we present a procedure by which this adjustment cost can be approximated.

\subsection{Separability of the Investment Problem}

Under the assumptions we made for the private sector, namely that there are no constraints to international borrowing, we have that all projects with positive net present value can and will be financed. Of course, this result stops holding, say, when moral hazard or adverse selection problems limit the availability of credit for local entrepreneurs. If the government faces fewer informational asymmetries than international lenders, there may be a role for government support of investment projects.

\subsection{Tax Smoothing}

In a fundamental result, Barro (1974) provided conditions under which the optimal consumption path does not depend on how the government finances its expenditures (debt vs. taxes). This result is known as Ricardian equivalence. When taxes are distorting, Ricardian equivalence does

\footnotetext{
${ }^{12}$ Of course, if producing countries sell part of their oil using future and forward contracts, the budget uncertainty will be less important.
} 
not hold and all sources of finance should be used in such a way that the marginal distortion they introduce is the same over time and across financing instruments. This result is referred to as "tax-smoothing", see, for example, Barro (1979).

\section{Intergenerational Redistribution}

In this section we discuss the problem of how to distribute oil wealth across generations. We analyze the degree to which two well known approaches to optimal fiscal policy correspond to particular cases of the framework developed in Section 2 and offer a new approach to deal with this problem.

\subsection{Benchmark Model}

The following model will be a useful benchmark throughout this section.

(a) Social welfare function: Utilitarian with constant elasticity of substitution across time $(1 / \rho)$. The initial population is normalized to one and grows at a constant rate $n$. The time horizon is infinite and there is no income uncertainty. Then (4) becomes:

$$
\mathcal{U}=\sum_{t=0}^{\infty} \beta^{t}(1+n)^{t} u_{t}^{1-\rho}
$$

The instantaneous utility has consumption of the public and private goods as separate arguments and the elasticity of substitution between both consumption goods is constant $(1 / \gamma)$ as in (2).

(b) Policy Instruments: The government is the only provider of the public good, which it finances with taxes, debt and proceeds from the sales of the government owned natural resource (oil in what follows). Oil income in period $t$ is denoted by $Y_{G, t}$; it is known with certainty and determined exogenously.

The government collects taxes and makes transfers to the private sector without generating any distortions in doing so. The government may also save and borrow at the international gross rate $R$. The only constraint it faces in setting taxes and borrowing is its intertemporal budget constraint (13). Initially it holds financial assets equal to $F_{G, 0}$.

\section{(c) Private Sector:}

Consumers live for one period and have no bequest motive; it follows that the private sector holds no assets or debt. Private sector production in period $t$ is exogenous and equal to $Y_{P, t}$. 
Total production in period $t$ is denoted by $Y_{t}$ and equal to $Y_{G, t}+Y_{P, t}$. In general, we denote aggregate variables by upper case letters, and per capita variables by lower case letters.

Constant elasticity of substitution between both goods implies that in the solution to the problem posed above the ratio of their consumption levels remains constant over time (see Lemma A.1 in the Appendix):

$$
\frac{c_{G, t}}{c_{P, t}}=k^{1 / \gamma}
$$

Denoting

$$
c_{t} \equiv c_{G, t}+c_{P, t}
$$

we have that $u_{t}$ is proportional to $c_{t}$ (Lemma A.1), so that we may write (14) as:

$$
\mathcal{U}=\sum_{t \geq 0} \beta^{t}(1+n)^{t} c_{t}^{1-\rho} .
$$

We denote society's initial wealth by:

$$
\mathcal{W}_{0} \equiv F_{0}+\sum_{s \geq 1} R^{-s}\left[Y_{G, s}+Y_{P, s}\right]
$$

We define:

$$
\begin{aligned}
\alpha & =(1+n)[\beta R]^{1 / \rho} \\
\tilde{\alpha} & =\frac{\alpha}{R}
\end{aligned}
$$

and assume $\tilde{\alpha}<1$.

In the Appendix (Proposition A.1) we show that the solution to this problem is given by:

$$
\begin{aligned}
c_{0} & =(1-\tilde{\alpha}) R \mathcal{W}_{0}, \\
c_{t+1} & =[\beta R]^{1 / \rho} c_{t} .
\end{aligned}
$$

If $\beta R=1$, the right hand side of (18) is society's permanent (total) income (Friedman, [1957]), that is, it is the highest per capita consumption level that can be maintained indefinitely.

Equation (15) determines how $c_{t}$ is split between consumption of the private and public good, thereby determining government expenditures.

The evolution of total financial assets can be determined as follows: $F_{1}$ is calculated using the dynamic budget constraint (11), the expression for $C_{0}$ given above and the (exogenously given) values of $F_{0}$ and $Y_{0}$. The dynamic budget constraint can then be used recursively to obtain $F_{2}, F_{3}, \ldots$

The current account is given by (see Proposition A.1 in the Appendix):

$$
C A_{t}=\left(2-\frac{1}{R}\right)\left(Y_{t}-C_{t}\right)+\left(1-\frac{1}{R}\right) F_{t} .
$$


The absence of bequests and the assumption that individuals live for one period imply that the private sector will accumulate no assets. Hence $F_{G, t}=F_{t}$ and the current account surplus is equal to the government's total (including interest receipts) surplus. Furthermore, optimal per capita taxes, $\tau_{t}$, are equal to:

$$
\tau_{t}=c_{P, t}-y_{P, t}
$$

\subsubsection{Examples}

Example 4.1 (Constant Non-oil Production) We assume no population growth $(n=0), R=$ 1.06, $\beta R=1,{ }^{13}$ and no initial financial assets $\left(F_{0}=0\right)$. The optimal mix of the public and private goods requires that the former represent $20 \%$ of total consumption. ${ }^{14}$

Initial oil production, which accrues to the government, accounts for $80 \%$ of GDP, while the remaining $20 \%$ is produced by the private sector. Oil production remains constant (in real terms) for 25 periods, moment at which oil reserves are exhausted. Production in the non-oil sector remains constant indefinitely.

Figure 4.1 shows the evolution of consumption, financial assets (as a fraction of non-oil GDP), and the current account (also as a fraction of non-oil GDP). The first two series are divided by 100 and 50, respectively. It can be seen that consumption remains constant and equal to the annuity value of initial wealth (both from the oil and non-oil sectors). During the "boom years" of oil production, assets are accumulated (by the government) to maintain a level of consumption above production once oil is exhausted. During the boom years we also observe a positive and, due to interest payments, increasing current account surplus, which turns into a constant deficit once oil is exhausted. Since oil revenues can finance more than the optimal level of the public good, the government transfers a fixed amount (not shown in the figure) to every generation.

It is interesting to note that if $\beta R<1$ (impatient individuals), the consumption path will be downwards sloping instead of constant, since individuals want to consume more and save less today. If this effect is large enough, there may be no initial current account surplus, as individuals spend more than the sum of their private income and the current oil income.

Example 4.2 (Increasing Non-oil Production) Assume now that, instead of remaining constant, non-oil production grows $2 \%$ per period forever. The remaining assumptions are the same as in the previous example.

Figure 4.2 shows the evolution of the same three variables considered in Figure 4.1, with the same normalizing constants. It also shows the path of optimal taxes (as a fraction of non-oil GDP). Consumption is constant, at a level 12.3\% higher than in Figure 4.1, reflecting the fact that non-oil

\footnotetext{
${ }^{13}$ This assumption makes the value of $\rho$ irrelevant in this problem.

${ }^{14}$ This is equivalent to having $k^{1 / \gamma}=4$.
} 
production increases over time, instead of remaining constant, as in the case of Figure 4.1. Assets increase during the years when oil is produced and are depleted thereafter, eventually approaching a constant (and negative) fraction of GDP. There is an increasing current account surplus during the boom years and a slightly decreasing current account deficit after oil is exhausted.

In contrast with Example 4.1, in this case taxes, as a fraction of non-oil GDP, do not remain constant. Initially the private sector receives large government transfers. These transfers decrease steadily, and individuals must begin paying taxes in period 67. From then onwards taxes increase significantly, so as to pay back the debt incurred by the government during the oil boom.

Example 4.2 shows that the Benchmark Model (BM) may lead to significant wealth transfers from future to current generations. The government may borrow against incomes from future generations to increase current consumption. It is interesting to note that the model has this implication even in the absence of oil wealth, as long as per capita private sector production increases over time. Since such large intergenerational transfers are rarely observed, this raises the issue of whether the BM provides an adequate criterion for deciding how to spend the revenue generated by oil production. We return to this issue in section 4.3 .

\subsubsection{Incorporating a Bequest Motive}

The expressions derived in the BM up to equation (20) also hold when individuals have a bequest motive. In this case the government chooses taxes and production of the public good so that private consumption chosen by individuals corresponds to the optimal value. The only difference is that now the private sector will have non-zero financial assets, so that optimal tax rates will differ from those obtained in (21). In particular, if the private sector's bequest motive is the same as the one implicit in the Social Welfare Function, so that the problem at hand is equivalent to that of an infinite horizon representative agent, the path of taxes is not determined. Any path consistent with the intertemporal budget constraint achieves optimal fiscal policy (Ricardian equivalence). Alternatively, if taxes are distortionary, tax-smoothing considerations will imply a unique optimal path for taxes.

\subsection{Permanent Oil Income Model}

The BM prescribes that permanent total income should be constant over time. Since this may lead to large wealth transfers across generations, it may be better to focus on permanent oil income instead:

"Because most export revenue from oil and natural gas accrues to the public sector, the central government usually decides through the budgetary process how much of this 
revenue will be saved and consumed. To make this decision based on intergenerational equity considerations, it is necessary to determine the permanent rent available from hydrocarbon exploitation. This rent represents the level of public consumption that can be currently enjoyed without increasing the country's debt and depleting its wealth."15

This approach can be rationalized within the framework of Section 2 as follows:

(a) Social welfare function: The difference with the BM is that the instantaneous utility function only depends on consumption of the public good. ${ }^{16}$

(b) Policy Instruments: The difference with the BM is that the government cannot collect taxes.

(c) Private Sector: The private sector does not appear, at least explicitly, in the problem.

The Permanent Oil Income Model (POIM) considers the problem of spending the government owned oil as if it were totally unrelated to the private sector's consumption of private goods. The solution to the problem is obtained by substituting total initial government wealth for total wealth in (17):

$$
\mathcal{W}_{G, 0} \equiv F_{G, 0}+\sum_{s \geq 0} R^{-s} Y_{G, s}
$$

We then have:

$$
\begin{aligned}
C_{G, 0} & =(1-\tilde{\alpha}) R \mathcal{W}_{G, 0}, \\
c_{G, t+1} & =[\beta R]^{1 / \rho} c_{G, t} .
\end{aligned}
$$

If $\beta R=1$, the right hand side of (23) (divided by period 1 population) is permanent oil income, that is, the highest per capita consumption level from oil resources that can be maintained indefinitely, thereby justifying the name of the model.

The POIM can be used to rationalize the often mentioned criterion of intergenerational fairness according to which oil wealth (either in absolute or per capita terms) should be kept constant. Equations (23) and (24) imply that per capita government wealth, which in this model corresponds to oil wealth, remains constant along the optimal consumption path only if $\beta R=1 .{ }^{17}$ If $\beta R<1$, it is optimal for society to deplete oil wealth as time goes by. It also follows from (23) and (24) that total oil wealth remains constant along the optimal consumption path only if $\beta R(1+n)^{\rho}=1$. If $n>0$ this requires a relatively impatient society, since $\beta R<1$.

\footnotetext{
${ }^{15}$ Quoted from Fasano (1999, p. 1).

${ }^{16}$ That is, it corresponds to the particular case of (2) where $k=0$.

${ }^{17}$ To derive this result evaluate $(23)$ at $t$ and $t+1$, instead of $t=0$, and equate the corresponding ratio to that obtained from (24).
} 
An advantage of the POIM, compared with the BM, is that it avoids intergenerational wealth transfers of non-oil assets. It does so by assuming that private income and consumption of the private good do not interact at all with the government's income and consumption of the public good. Next we present two unattractive consequences of this limitation, one that can be accommodated with a straightforward extension of the model and one that cannot.

A first limitation is that the mix of privately and publicly produced goods will usually be suboptimal. The optimal path of the POIM determines the level of consumption of the public good without taking account of consumption of the private good chosen by consumers. This objection can be accommodated by assuming that consumers live for one period and have no bequest motive, and introducing a limited role for taxation: in every period the government sets taxes/transfers so as to ensure that the optimal mix of the public and private consumption goods is provided. That is, if we denote by $\hat{C}_{G, t}$ the consumption of the public good derived from the POIM, total consumption during period $t$ will satisfy:

$$
C_{t}=\hat{C}_{G, t}+Y_{P, t},
$$

where we have used the fact that consumers do not save.

A second example of the limitations of the POIM is illustrated by the following example. Assume that private income and oil income are perfectly negatively correlated. ${ }^{18}$ When oil income is high, private income is low and viceversa, so that total income (GDP) remains constant over time. Consumers live one period and do not save. The (certainty-equivalence version of the) POIM implies that only consumption of the public good will be smoothed out over time, so that total consumption will be high in years with high private income and low in years with low private income. Even though this is the optimal solution within this framework, common sense suggests that all generations would be better off if the government smoothed total consumption. Before knowing whether oil income or private income will be high during their lifetime, a generation prefers receiving its total permanent income for sure to receiving the sum of permanent oil income and private income. Also note that the private sector cannot mitigate this limitation since, having ruled out taxation for intergenerational purposes, improvements of the sort described above are not possible. We conclude that in this example there exists a consumption path that is better (as measured by the BM) for all generations than the solution from the POIM. Furthermore, ex-ante, this improvement involves no intergenerational transfers on average.

\subsubsection{Examples}

Example 4.3 (Constant Non-oil Production) We solve the POIM under the parameter values of Example 4.1. Since non-oil income is constant over time, the solution to the BM does not require

\footnotetext{
${ }^{18}$ This example is used to make a point, the assumptions do not hold in practice but the validity of the point does.
} 
intergenerational wealth transfers. It follows that the solution to the POIM is the same as that of the BM. Disregarding consumption of the private good when choosing the optimal consumption path is of no consequence in this case.

The equivalence between both optimal paths breaks down if we assume $\beta R<1$. In this case, the increasing consumption path prescribed by the BM will be steeper than the one prescribed by the POIM.

Example 4.4 (Increasing Non-oil Production) We modify the previous example by assuming that non-oil GDP grows at $2 \%$ per period. Optimal consumption of the public good is constant and total consumption increases over time at the same speed as private income. The optimal consumption path is the path of private income shifted by the permanent oil income. The optimal consumption path differs significantly from that obtained in Example 4.2. The government accumulates financial assets while oil is extracted, but asset accumulation is considerably less than in the solution to the BM, since the government is not allowed to use taxes to make intergenerational wealth transfers.

It follows from both examples above that if oil wealth is front loaded and individuals are not very impatient, the country should save part of the resource proceeds. The counterpart of these savings is a persistent fiscal and current account surplus for some time. This is the main conclusion in Alier and Kaufman (1999), who work with a model that has the SWF of the Benchmark Model but assume constant and exogenous taxes, thereby avoiding intergenerational wealth redistribution. The latter assumption makes their problem equivalent to our POIM, with identical policy prescriptions and limitations. ${ }^{19}$

\subsection{A New Approach}

Both models discussed in the previous subsections have serious shortcomings. The Benchmark Model allows for intergenerational wealth transfers which we do not observe even in the absence of oil wealth. On the other hand, the POIM avoids intergenerational transfers by ruling out government policies that benefit all generations (as viewed from the BM). The Benchmark Model's SWF is more appealing than that of the POIM, since individuals benefit both from consumption of the private and public goods. Regarding instruments, the BM has more than we would like, while the POIM eliminates unattractive instruments (intergenerational wealth transfers) at the cost of ruling out appealing policy alternatives.

The challenge therefore is to limit the policy instruments available to the government in the BM in such a way that the attractive properties of both models can be recovered. We propose

\footnotetext{
${ }^{19}$ Their generations live for two periods, yet no additional insight is gained from this assumption. Also, the mix of public and private good provided is typically not optimal.
} 
the following approach. Add to the BM the restriction that no generation can be worse off than it would have been in the absence of oil wealth, where the counterfactual with no oil wealth should be determined by positive considerations.

The approach we propose, which we describe as conditionally normative, does not undo what society would have done in the absence of oil. Instead it spreads the wealth of oil across generations optimally, not by giving every generation the same amount of the public good, as in the simplest POIM, but by choosing among all possible policies that are Pareto improving, the one that increase the SWF the most. The additional constraint imposed by the Conditionally Normative Model (CNM) on the BM ensures that no intergenerational transfers of non-oil related wealth take place while allowing for an efficient allocation of oil wealth.

Denote instantaneous utility in period $t$ by $u_{t}$, and instantaneous utility in the absence of oil income by $u_{t}^{*}$. Applying the CNM in period 1 requires choosing a among all possible consumption paths that satisfy $u\left(c_{t}\right) \geq u_{t}^{*}, t \geq 0$, the one that maximizes the SWF considered in the BM. If there is income uncertainty, then the constraint becomes $\mathrm{E}_{0}\left[u\left(c_{t}\right)\right] \geq \mathrm{E}_{0}\left[u_{t}^{*}\right]$, where $\mathrm{E}_{0}$ denotes expectations based on information available in period 0 .

\subsubsection{Examples}

We consider three examples to illustrate the CNM.

Example 4.5 (Constant Non-Oil Income) Assume that non-oil GDP remains constant over time and $\beta R=1$ (see Example 4.1). In this case the three approaches considered in this paper, the $B M$, the POIM and the CNM, imply the same constant path for consumption.

Almost any departure from the simple case described above will result in different consumption paths for the three models. The following two examples consider changes in future non-oil income.

Example 4.6 (Increasing Non-Oil Income) Figure 4.3 shows the consumption path associated with the three models when non-oil income grows $2 \%$ per period, for the first 50 periods, and remains constant thereafter. ${ }^{20}$ Optimal (total) consumption in the BM is constant. In the POIM it grows together with non-oil income, the difference between both series being equal to the annuity value of oil wealth. Optimal consumption in the CNM is constant during the first 18 periods and follows the path of non-oil income thereafter.

Compared with the POIM, those living in the first 12 periods are better off under the CNM while those living thereafter are worse off. Since marginal utility of consumption in the absence of oil is higher during the initial periods, the CNM spreads the oil wealth among those living in these periods.

\footnotetext{
${ }^{20}$ The remaining parameter values are: $R=1.04, \beta R=1, n=0$, oil wealth is 100 and initial non-oil income is 30 .
} 
Those that benefit the most are those that would have been poorest without oil wealth-generations that expected relatively high private incomes do not benefit at all.

Example 4.7 (Decreasing Non-Oil Income) Figure 4.4 shows what happens when non-oil income decreases by $2 \%$ during the first 50 periods, and remains constant thereafter. ${ }^{21}$ The behavior of the optimal consumption path in the BM and POIM are qualitatively similar to those described in the previous example. In the case of the CNM, optimal consumption decreases initially, being equal to non-oil income during this phase. Eventually (period 13 in the figure) it stops decreasing and remains constant thereafter. By contrast with Example 4.6, in this case the optimal consumption path of the CNM is fiscally more conservative than that of the POIM. It prescribes not spending oil related wealth during early years, saving it to help those who expect to be worse off in the future. Only in period 13 the CNM recommends to begin spending oil wealth to help maintain the highest consumption level compatible with the restriction of not leaving any generation worse off than it would have been without oil. It is also interesting to note that in this example the consumption path of the Benchmark Model is the one that is most conservative from a fiscal point of view. It taxes heavily the initial generations to finance a constant level of consumption for everybody.

The following general result for the optimal consumption path under CNM is presented in the Appendix (Propositon A.2). It assumes no income uncertainty and $\beta R=1$. Under these assumptions, the optimal consumption path for the CNM can be found as follows: First, the generations are ordered according to their utility in the non-oil scenario. Next, oil wealth is used to raise the income of the poorest generation until it equals that of the second poorest. If this does not exhaust the oil wealth, the income of the two poorest generations is raised until it equals that of the third poorest. And so on until no oil wealth remains to be distributed. If oil wealth is large enough so that the income of all generations can be brought to the level of the richest generation (in the scenario without oil), the constraint that differentiates the CNM from the BM is not be binding and both optimal consumption paths are the same (constant, equal to the annuity value of total wealth). Otherwise, the richest generations do not benefit from the oil wealth.

\section{Oil Related Uncertainty}

Characterizing the stochastic process that oil prices follow and evaluating the possibility of forecasting them are key ingredients when designing optimal fiscal policy rules for oil producing countries. For instance, recommendations regarding both the decision to adjust or finance a given price (terms of trade) shock and the design of an optimal oil stabilization fund depend of what is expected to happen with future prices, including their distribution. If each and every shock is regarded as

\footnotetext{
${ }^{21}$ The remaining parameter values are those of Figure 4.3 .
} 
having permanent effects and there are no adjustment costs in fiscal policy, then countries should completely lean towards adjustment. This section analyzes the ability of time series models to forecast future oil prices. We exclude large structural models both because replicating out-of-sample forecasts often is impossible and because their forecasting ability typically is worse than that of time series models. ${ }^{22}$

Before presenting and discussing results we mention an important limitation of this section. What matters for fiscal planning is government income uncertainty, which corresponds closely to oil income uncertainty in the cases considered in this paper. Since this chapter considers price uncertainty, we are implicitly assuming a constant rate of extraction (given by OPEC). In reality the correlation between oil production and oil prices is likely to be negative, so that we may be overestimating the importance of shocks. Unfortunately, we do not have enough data on non-oil income to work with this variable directly (and the data we have show strange patterns).

\subsection{Previous Literature}

In this subsection we present a short review of the recent literature of oil price forecasts based on time-series models. It is understood throughout that models under consideration are for the logarithm of the oil price.

The benchmark model to forecast oil prices (as well as other commodity prices) at medium run horizons, say 1 or 2 years, is a random walk, with and without drift. In this case the best prediction of future prices is the spot price (probably plus a drift). Furthermore, every shock to prices is permanent, affecting all expected future prices. The intuition for having this simple process follows from thinking about oil as an asset. Arbitrage prevents the existence of predictable price jumps for they offer an opportunity of making (potentially) unlimited profits. A drift reflects a fixed broad opportunity cost of maintaining the asset. ${ }^{23}$

The idea that oil prices follow a random walk, however, is at odds with the presumption that production of both oil and its substitutes should increase at higher oil prices. At the same time, oil production should decrease if prices are below marginal costs. By contrast, if prices follow a random walk, they could increase without bound and/or approach arbitrarily close to zero. ${ }^{24}$ Despite this notion, it is not easy to reject the random walk hypothesis. Researchers have either used extremely long samples to find mean reversion or have had to resort to less standard approaches, where by "standard approaches" we mean the Augmented Dickey-Fuller (ADF) and Phillips-Perron (PP) tests.

\footnotetext{
${ }^{22}$ See Powell (1990) and Pindyck (1999).

${ }^{23}$ This opportunity cost could be negative if there is a low storage cost, a low real interest rate and good business opportunities for those who have oil in storage (convenience yield).

${ }^{24}$ Furthermore, it can be shown that, with probability one, they eventually do one of the two.
} 
For example, with several years of data, Videgaray (1998) finds mean reversion after allowing for a structural break in $1973 .{ }^{25}$ Pindyck (1999) rejects the random walk null hypothesis using an ADF unit root test only after considering more than 70 years of data. Interestingly, he concludes that even with 120 years of data, permanent shocks do exist (although their size is considerably smaller than that of the transitory shocks). Finally, Bessembinder et al. (1995) find evidence of mean reversion using the future prices term structure.

The difficulty in rejecting the random walk hypothesis has led to more sophisticated models to describe oil prices. Rather than assuming reversion to a constant trend, Pindyck (1999) proposes a model in which both the constant and the trend are, in turn, non observable mean reverting stochastic processes. He estimates this model with a long sample of annual data using a Kalman Filter, and predicts prices 20 years ahead. Although no formal tests are provided, the forecasts appear to be better than those of a fixed trend AR(1) process. Of course, there is always the question of whether it is valid to use pre 1973 data to forecast future prices given the large structural break that took place at that time.

Schwartz (1997) also presents Kalman Filter estimates and formally compares the forecast capability of three alternative models for future and forward prices using high frequency data spanning 11 years. He considers a one factor model in which the (logarithm of the) oil price follows an AR(1) process, a two factor model in which the convenience yield is stochastic, and a three factor model in which a stochastic interest rate is also included. The estimation procedure he uses takes into account that the spot price, the convenience yield and the interest rate are not perfectly observable - thus the need of the Kalman Filter. The results he obtains indicate that including a second factor (the convenience yield) improves substantially the forecast capability of the model.

A simple random walk, an AR(1), and the models presented in Pindyck (1999) and Schwartz (1997) can be thought of as special cases of the following model:

$$
p_{t}=\alpha_{t}+\delta_{t} \operatorname{Trend}_{t}+\psi_{t} p_{t-1}+\varepsilon_{t}
$$

where $p_{t}$ is the $\log$ of the real oil price, $\alpha_{t}, \delta_{t}$ and $\psi_{t}$ are possibly stochastic parameters, Trend $d_{t}$ is a time trend and $\varepsilon_{t}$ is a stochastic stationary shock.

A random walk with drift assumes $\alpha_{t}$ constant, $\delta_{t}=0$, and $\psi_{t}=1$ (as well as $\varepsilon$ white noise). An $\operatorname{AR}(1)$ assumes a constant $\alpha_{t}$, a constant $\psi_{t}<1$ and (possibly) a positive $\delta_{t}$.

More interestingly, Pindyck (1999) considers that both $\alpha_{t}$ and $\delta_{t}$ follow unobservable AR(1) stochastic processes with uncorrelated innovations. These processes are meant to represent reduced forms for the effects of demand, cost of extraction and available reserves shocks. Prices then would revert to a changing trend (level). Also, Schwartz (1997) considers the possibility that in his two

\footnotetext{
${ }^{25}$ He uses the Perron (1989) test which basically augments the standard Augmented Dickey-Fuller test to take into account structural breaks in levels and/or slope of a series.
} 
factor model $\psi_{t}$ follows a stochastic process (possibly mean reverting) with innovations that can be correlated with innovations of the current spot price. The economic interpretation of this model is that the convenience yield follows a process itself. The intuition for why this variable affects current spot prices is simple: If oil represents an asset, then the current and future spot prices are linked through the current interest rate, storage costs and the convenience yield. Thus, for a given future spot price, a higher convenience yield will increase the current spot price.

We will use these alternative models below to evaluate the extent to which oil prices can be forecast.

\subsection{Revisiting the Random Walk Hypothesis}

A key issue that we face is the question of to what extent future oil price changes can be predicted. In one extreme, it is possible to think that oil prices follow a simple random walk. If that were the case, then the best prediction for all future periods is the current value, while the standard deviation of this prediction grows linearly with time. In the other extreme, one could think of oil prices following a stationary process, where it is possible to forecast future prices with greater precision.

In order to evaluate the forecastability of oil prices we present below three group of tests: standard ADF and PP, Variance Ratio, and non-linear adjustment. In all cases we consider quarterly observations of the log of the real price of Brent oil (using the US WPI as the deflator).

\subsubsection{ADF and PP Tests}

Augmented Dickey-Fuller and Phillips-Perron tests are the standard procedures to evaluate whether a series follows a stationary process. Intuitively, these tests measure the strength of the forces that tend to move the series back to a constant trend after suffering a shock. If the strength of these forces is low, then one concludes that the process is non stationary (that there is no mean reversion).

Table 5.1 presents the results for three alternative samples of quarterly data: 1957.I-1999.II, 1974.I-1999.II, and 1986.I-1999.II, and two specifications with and without trend. The test shows that when the larger sample is considered, the process appears to be non stationary. In contrast, the shorter samples, particularly 1986.I-1999.II, suggest a stationary process.

This evidence shows that when one excludes large changes in regime, oil prices appear to be stationary. However, when these regime shifts are considered, price shocks tend to have relevant permanent effects. In terms of forecastability, these results show that assuming a stationary process is a valid procedure as long as one assumes that the current regime will prevail with probability one. More generally, however, one could improve the forecast by considering and modeling the transitory or permanent components of a shock. 


\subsubsection{Variance Ratio Test}

The second type of test we consider to evaluate whether oil prices follow a non-stationary process is the Variance-Ratio (VR) Test. This test makes use of the linearly increasing volatility of a nonstationary process and evaluates whether the standard deviation measured at different horizons increases as predicted under the null of random walk. Furthermore, it gives a measure of the relative importance of transitory and permanent shocks.

In particular, the VR test calculates a statistic $J(s), s=1,2, \ldots, S$ that has the following properties. ${ }^{26}$ As the sample size becomes large and $s$ increases the ratio $J(s) / s$ should converge to zero if the true process is stationary. If it does not converge to zero the process is non-stationary. Moreover, the value to which $J(s)$ converges represents the standard error for long term forecasts. These properties hold as long as the sample size is large and $s$ is considerably smaller than this sample size.

Figures 5.1 and 5.2 present the results of VR tests for the log of the oil price for two samples: 1957.I-1998.IV and 1974.I-1998.IV. In both cases the statistic $J(s) / s$ does not converge to zero, showing that the shocks to the true process probably have some permanent effects. The size of these effects appears clearly smaller than the standard deviation of the innovations of a simple random walk estimated for each sample. This fact shows that shocks also have some transitory effects on prices, suggesting that it should be possible to do better, in terms of forecasting, than with a random walk.

One important limitation of these results is that the sample sizes we consider are not very large compared to $s$. In order to evaluate how this issue may affect the results the figures also present the results of a Montecarlo experiment considering a sample of equal size to what we consider in the calculations. These Montecarlo experiments are based on 1000 replications of a process that has the same standard deviation and parameters as the true data.

The results of these experiments show that, indeed, the small sample affects the performance of the test (for the sample sizes we consider). The statistic $J(s) / s$ for a true random walk decreases instead of converging to a flat value. At the same time, a true AR(1) does not converge to zero for the values of $s$ we consider (although it does not converge to a positive value either). These results, however, do not change our general interpretation of the process. Because the sample statistic decreases faster than for the random walk, we conclude that shocks do not have full permanent effects. And because it tends to converge to a positive value, we conclude that shocks do not have transitory effects only.

\footnotetext{
${ }^{26}$ See Hamilton (1994) for further details.
} 


\subsubsection{Non-linear Adjustment}

One potential explanation for finding evidence of non-stationarity when the true process is actually stationary is the existence of non-linearities in the adjustment process. It could be the case, for example, that oil prices follow a random walk within certain range. Outside this range, however, there could be forces that bring oil prices back. The intuition that prices cannot permanently be below marginal costs and that above certain threshold oil substitutes enter the market is in line with this interpretation.

More generally, oil prices may be viewed as the sum of two processes, with the relative importance of both processes dependent on the price level. Prices follow a unit root or even an explosive process for small deviations from a stationary trend, but the process becomes mean-reverting for large deviations. This is the case, for example, of exponential and logistic smooth-transition autoregressive (ESTAR and LSTAR) models. In this case it is assumed that mean-revering forces appear gradually as the actual oil price deviates from its long run equilibrium value. ${ }^{27}$ Threshold autoregressive models (TAR) are another type of models in which the transition from unit-root to mean-reverting occurs suddenly at a fixed threshold.

In order to test the hypothesis of linearity in the oil price process we follow the procedures described in Michael et al. (1997). In particular, we test the null hypothesis of linearity against a smooth-transition model by using OLS to estimate the model:

$$
p_{t}=\beta_{00}+\sum_{j=1}^{k}\left(\beta_{0 j} p_{t-j}+\beta_{1 j} p_{t-j} p_{t-d}+\beta_{2 j} p_{t-j} p_{t-d}^{2}\right)+\varepsilon_{t}
$$

for alternative values of $d$. The null hypothesis is $\beta_{1 j}=\beta_{2 j}=0(j=1, \ldots, k)$. Linear adjustment is rejected if for any of the values of $d$ the p-value of this test is insignificant.

Table 5.2 presents the p-values that result from testing the null hypothesis of linearity of log real oil prices using different samples and three alternatives values for $d$. It also shows the value of $k$, the lags required to have white-noise innovations in each case. The results show that the linear adjustment hypothesis is rejected only in the sample 1974-1999 using $k=d=1$. We find one rejection in three as relatively weak evidence in favor of non-linear adjustments. In what follows we focus mainly on linear models, but keep as a competing alternative the non-linear model with $d=1$.

\subsection{Evaluation of Alternative Models}

The usefulness of a forecasting model has to be measured out of sample. Ultimately it is the ability to forecast future unknown prices that should discriminate among competing models. In

\footnotetext{
${ }^{27}$ See Michael et al. (1997) for an application to non-linear adjustment of real exchange rates towards PPP values.
} 
this subsection we evaluate the out of sample forecast capabilities of 12 alternative linear models, a non-linear model, market future prices, and market forecasts.

We consider two alternative samples, one starting in 1974 and the other starting in 1986, and calculate the root mean square error (RMSE) of forecasts at 1 and 2 year horizons proceeding as follows. We estimate repeatedly each model using quarterly data (and weekly data in one case) ending in the second quarter of the years 1994 to 1998 and forecast out of the estimating sample. Then we compute the RMSE using the forecast errors at 1 and 2 years horizons. For each model we have 5 one-year ahead and 4 two-year ahead forecast errors.

The linear models we consider (for the logarithm of the real price of oil) are the following:

1. A random walk without drift.

2. A random walk with drift.

3. An $\operatorname{ARIMA}(2,1,2)$. This model is the equivalent of a random walk augmented by a stationary process for the error term $\varepsilon_{t}$.

4. Same as above with a dummy variable that take the value 1 during the invasion of Kuwait in 1991.

5. An $\operatorname{AR}(1)$ without drift (assuming that the process is stationary).

6. The permanent value of a Beveridge and Nelson decomposition of the series. ${ }^{28}$

Models 7 through 11 consider an AR(1) model with stochastic first-order autocorrelation, $\psi_{t}$, which is estimated using the Kalman Filter. The models differ in the assumptions they make on the process followed by $\psi_{t}$ and whether they include a linear trend or not for the price process.

7. The price process has no trend and $\psi_{t}$ follows a random walk with innovations orthogonal to those of the price process.

8. As 7 but with a trend in the price process.

9. The price process has no trend and $\psi_{t}$ follows an $\operatorname{AR}(1)$ process with innovations that are orthogonal to oil price innovations (this model resembles model 2 of Schwartz, 1997).

10. As 9 but with a trend in the price process.

\footnotetext{
${ }^{28}$ The Beveridge and Nelson decomposition identifies that permanent component of a series as the long run value at which the series would tend if there are no further shocks. It predicts future prices using a rolling ARIMA model $([2,1,2]$ in this case $)$.
} 
11. Both the constant and the trend parameters of the price process follow AR(1) processes with innovations that are orthogonal to oil price innovations and between them (this model is based on Pindyck, 1999).

12. As 7 but using weekly data to estimate the model (this model is based on Schwartz, 1997). The forecast is also weekly and we average the forecasts to calculate MRSEs. The data we consider in this model is slightly different because prices are not deflated.

We also consider three other forecasts in the out-of-sample evaluation. We estimate repeatedly the non-linear ESTAR model discussed above with the same quarterly data and forecast prices one and two year ahead using the estimated model. Finally, we consider the one-year ahead future price from Bloomberg (for June delivery) and the average surveyed one year ahead forecast informed by the June issue of Consensus Forecast. ${ }^{29}$

Table 5.3 presents the results of this exercise. Notwithstanding the fact that the RMSE are calculated with small samples, the results show that more sophisticated models do not have a better out-of-sample performance. Indeed, the models with stochastic autoregressive parameter are clearly outperformed by a simple random walk. The model with stochastic trend and constant appear to be as good as the random walk. Overall, only the ARIMA models (with and without dummies for the Kuwait invasion) appear to perform somewhat better than the random walk without drift. When we use the longer sample to estimate each model the best performance corresponds to the ARIMA model without dummies. For the short sample the best performance corresponds to the ARIMA model with dummies. Yet if we consider both samples jointly, it is hard to argue than any model does significantly better than the random walk without drift. ${ }^{30}$ Furthermore, this model appears to be only marginally less accurate than surveyed forecasts.

\section{Precautionary Saving and Adjustment Costs}

In this section we present some useful approximations to the optimal consumption plan explicitly considering that future income is uncertain and that there are adjustment costs. In order to simplify matters we consider one issue at a time and a setup in which in absence of uncertainty and adjustment costs, the POIM is a correct description of the problem. This description also corresponds to the $\mathrm{BM}$ and the $\mathrm{CNM}$ when $\beta R=1$ and non-oil GDP is constant in per capita terms. Furthermore, given the results of section 5, we consider as our baseline case that oil price follows a geometric random walk. In the appendix we present the approximations for the $\operatorname{AR}(1)$ case.

\footnotetext{
${ }^{29}$ In the latter two cases prices are nominal and refer to West Texas prices.

${ }^{30}$ We also calculated the RMSE of 5-year-ahead forecasts using samples that ended in 1991 Q2 for both a .random walk and a $\mathrm{AR}(1)$ process. The results (not reported) show a smaller RMSE for the random walk.
} 


\subsection{Income and Budget Uncertainty}

Income uncertainty - the risk about future income realizations - can be incorporated easily into consumption models. If the instantaneous utility is quadratic, we have certainty-equivalence, and the results obtained in Section 4.2 need to be modified only slightly. For example, equations (18) and (19) become:

$$
\begin{aligned}
c_{0} & =(1-\tilde{\alpha}) R \mathrm{E}_{o}\left[\mathcal{W}_{0}\right], \\
\mathrm{E}_{t}\left[c_{t+1}\right] & =[\beta R] c_{t},
\end{aligned}
$$

where $\mathrm{E}_{t}$ denotes expectations based on information available in period $t$. That is, all that changes is that uncertain quantities are replaced by their expected values. Of course, as mentioned in Section 3.2, this solution has the awkward property that current savings do not depend on the variance of future income.

In the more appealing case of a CES instantaneous utility, there does not exist a simple expression for $c_{0}$. The solution has to be found resorting to numerical methods. We propose instead an approximation to the optimal solution that is transparent and easily implementable. Of course, because it is an approximation it does not correspond exactly to the optimal solution.

Our procedure is based on a counterfactual experiment in which consumption decisions are made knowing that oil risk is diversified away in the near future, say that the oil industry will be privatized. This procedure allows us to simplify the consumption problem by collapsing all future periods in a single period and treating the overall problem as a two-period problem. Furthermore, assuming that the variance of oil price shocks is small, we can write a closed-form solution for consumption as a function of that variance and initial conditions.

More precisely, consider the period $t$ optimal consumption decision knowing that the oil industry will be privatized in period $t+1$. Because in period $t+1$ all income uncertainty is resolved, from that moment onwards the consumption problem is trivial: under the assumption $\beta R=1$ the solution is to consume the sum of the annuity values of the privatization proceeds and the financial assets available at that time. Assume, further, that oil risk is fully diversifiable in the world economy, so that the privatization proceeds equal the expected NPV of oil GDP conditional of the oil price observed in $t+1$. As of period $t$, the privatization proceeds is a random variable that depends on the oil price process. Moreover, it depends on the expected path of future oil prices.

Consider now the comparison of the optimal consumption decision of period $t$, knowing the oil price of that period, both under certainty equivalence (CE) and the optimal consumption level (given the actual volatility of the price process). The plan under CE corresponds to the POIM solution. The difference between the two consumption levels measures the precautionary savings motive. 
So far we have assumed that period $t$ oil prices are known at the beginning of the period, when consumption decisions are taken. However, when deciding next year's budget, policymakers do not know the level of oil prices that will finally prevail. This information problem corresponds to budget uncertainty. Although it is closely related to income uncertainty, it represents a different source of uncertainty. In order to derive closed-form solutions for the effects of budget uncertainty we consider that at the moment of writing the budget the price of oil at time $0, P_{0}$, is not known but assumed to follow a log-normal distribution with known mean and variance. This distribution captures all the information available to the government about the price of oil during the budget year being considered. Only from period 1 onwards does the (real) price of oil follows a geometric random walk with drift. The possibility of setting the parameters for the initial price allows us to depart from the pure random walk assumption, thereby allowing the incorporation of some degree of mean reversion.

Besides the counterfactual experiment of privatizing, we use approximations to obtain closedform solutions for consumption. In particular, we consider a first order Taylor approximation around the case in which the variances of both shocks to future prices and the current year (budget year) price are zero.

\subsubsection{Correction Factors}

Assume that oil prices follow the process:

$$
\log P_{t}=a+\psi\left(\log P_{t-1}\right)+v_{t}
$$

where $a /(1-\psi)$ represents the unconditional expectation of $\log P$ if $\psi<1$ or the drift of the process if $\psi=1$, and $v_{t}$ is an i.i.d. zero Normal shock with variance $\sigma_{v}^{2}$. Assume further that oil production starts at a level $Q_{0}$, growths at a constant rate $g$, and lasts for $T$ periods, when the resource is exhausted. ${ }^{31}$

Then production at time $t$ is:

$$
Q_{t}=\left\{\begin{aligned}
Q_{0}(1+g)^{t} & \text { if } t \leq T \\
0 & \text { if } t \geq T+1
\end{aligned}\right.
$$

while period $t$ income, $Y_{t}$, is given by $P_{t} Q_{t}$.

Moreover, assume that the initial price $P_{0}$ is unknown when the government has to determine its initial consumption. In particular, $P_{0}$ has mean $\mu_{P, 0}$ and variance $\sigma_{P, 0}^{2}$. Thus, initial income $Y_{0}$

\footnotetext{
${ }^{31}$ Given initial reserves $\tilde{\mathcal{Q}}_{0}$, initial extraction $Q_{0}$, and growth rate $g$, the duration of the resource is

$$
T=\frac{\log \left(1+g+\mathcal{Q}_{0}\right) / Q_{0}}{\log (1+g)} .
$$
}


has mean $\mu_{0}=\mu_{P, 0} Q_{0}$ and variance $\sigma_{0}^{2}=\sigma_{P, 0}^{2} Q_{0}^{2}$. Finally, assume that initial population is $N_{0}$ and growths at rate $n$.

Denote by $c_{0}\left(\sigma_{v}^{2}, \sigma_{0}^{2}\right)$ the optimal period 0 per capita consumption level considering both types of uncertainty. ${ }^{32}$ In the Appendix (Lemma B.1) we show that if $\sigma_{v}^{2}$ and $\sigma_{0}^{2}$ are small, this solution can be approximated by:

$$
c_{0}\left(\sigma_{0}^{2}, \sigma_{v}^{2}\right) \simeq\left[1-\Delta_{B U}-\Delta_{I U}\right] c_{0}(0,0)
$$

with

$$
\begin{aligned}
\Delta_{B U} & =-\frac{c^{1}(0,0)}{c_{0}(0,0)} \sigma_{0}^{2}, \\
\Delta_{I U} & =-\frac{c^{2}(0,0)}{c_{0}(0,0)} \sigma_{v}^{2} .
\end{aligned}
$$

Where $c_{0}(0,0)$ is initial consumption if there were no uncertainty and the superscripts denote derivatives with respect to argument $j(j=1,2)$.

In general, both correction factors comprise two components. One captures the precautionary motive and, as expected, is positive, so that resulting consumption is smaller than it would have been in the absence of this motive. The second component corresponds to an income effect due changes in initial wealth associated with variations in $\sigma_{0}$ and $\sigma_{v}$. For example, if the price of oil follows a geometric random walk and the mean of the innovations $v_{t}$ does not vary with $\sigma_{v}$, the present discounted value of oil income grows with $\sigma_{v}$ at a rate $\frac{1}{2} \sigma_{v}^{2}$. On the other hand, if the drift of the random walk $-\frac{1}{2} \sigma_{v}^{2}$ the negative drift cancels the effect of volatility on wealth and there is no income effect. Choosing between both alternatives is equivalent to deciding whether $\mathrm{E}_{t}\left[P_{t+1}\right]=P_{t}$ or $\mathrm{E}_{t}\left[\log P_{t+1}\right]=\log P_{t}$, both cannot hold due to Jensen's inequality. Since forecasts based on the former are more precise and income effects can be much larger than what common sense would suggest, ${ }^{33}$ we ignore income effects in what follows. ${ }^{34}$

Define $\varphi$ as the present discounted value of future income $\sum_{t=0}^{T-1} \beta^{t} Y_{t+1}$. In the appendix we show that the correction factors $\Delta_{B U}$ and $\Delta_{I U}$ are given by:

$$
\begin{aligned}
\Delta_{B U} & =\left.\frac{1}{2}(1+\rho) \frac{\beta(r-n)^{2}}{(1+n) N_{0}^{2} c_{0}(0,0)^{2}} \frac{\partial \operatorname{Var}_{0}\left(Y_{0}+\mathrm{E}_{1}[\varphi]\right)}{\partial \sigma_{0}^{2}}\right|_{\sigma_{v}=\sigma_{0}=0} \sigma_{0}^{2}, \\
\Delta_{I U} & =\left.\frac{1}{2}(1+\rho) \frac{\beta^{3}(r-n)^{2}}{(1+n) N_{0}^{2} c_{0}(0,0)^{2}} \frac{\partial \operatorname{Var}_{0}\left(Y_{0}+\mathrm{E}_{1}[\varphi]\right)}{\partial \sigma_{v}^{2}}\right|_{\sigma_{v}=\sigma_{0}=0} \sigma_{v}^{2} .
\end{aligned}
$$

Where $\rho$ is the coefficient of relative risk aversion. Both correction factors are proportional to the coefficient of relative prudence, $1+\rho .^{35}$

\footnotetext{
${ }^{32} c_{0}$ also depends on $\mu_{0}$ and $F_{0}$, but since these parameters remain constant in what follow they are omitted.

${ }^{33}$ Consumption after applying the correction factors cam be much larger than under certainty equivalence!

${ }^{34}$ Expressions that include the income effect may be found in Proposition B.1 in the Appendix.

${ }^{35}$ See Kimball (1990).
} 
The expression $c_{0}(0,0)$ that appears in both correction factors corresponds to optimal consumption when there is no income uncertainty and is therefore calculated using consumption smoothing. Since $c_{0}(0,0)$ is increasing in $F_{0}$ we shall have that both correction factors are decreasing in initial financial assets.

In the case of a geometric random walk the correction factors can be written as follows (Proposition B.2 in the Appendix considers the case where $\psi<1$ ):

$$
\begin{aligned}
\Delta_{B U} & =\frac{1}{2}(1+\rho) \frac{R}{(1+n)}\left\{1+\frac{1-\beta(1+g)}{1-\beta^{T+1}(1+g)^{T+1}}\left[\frac{F_{0}}{\mu_{0}}\right]\right\}^{-2} C V_{0}^{2}, \\
\Delta_{I U} & =\frac{1}{2}(1+\rho) \frac{\beta(1+g)^{2}}{(1+n)}\left\{\frac{1-\{\beta(1+g)\}^{T}}{[1-\beta(1+g)] \frac{F_{0}}{\mu_{0}}+1-\{\beta(1+g)\}^{T+1}}\right\}^{2} \sigma_{v}^{2},
\end{aligned}
$$

where $\mathrm{CV}_{0}^{2}=\sigma_{P, 0}^{2} / \mu_{P, 0}^{2}$.

If next year's budget were written knowing the price of oil on December 31st of this year, and all income uncertainty were summarized by the assumption that the price of oil follows a geometric random walk, we would have $\mathrm{CV}_{0}=\sigma_{v}$. The fact that budgets are written some months before December suggests that $\mathrm{CV}_{0}>\sigma_{V}$. On the other hand, selling a significant fraction of next year's oil production in futures markets reduces $\mathrm{CV}_{0}$. It follows that assuming $\mathrm{CV}_{0}=\sigma_{V}$ provides a convenient benchmark for practical applications.

\subsubsection{Examples}

In order to evaluate the importance of precautionary savings in the context of oil producing countries we present four examples. The first one presents a baseline case. The other three present comparative statics.

Example 6.1 (Precautionary Saving Correction Factors) We assume no population growth $(n=0)$, one inhabitant, no output growth $(g=0), R=1.05, \beta R=1, \rho=3, Q_{0}=100, \mu_{P 0}=25$, $\sigma_{v}=0.25, \sigma_{P, 0}=6.25, T=50$, and $F_{0}=2,500$ (equivalent to one year of production).

With these parameters the results are as follows. From an income of 2,500, the certainty equivalence consumption is 2,411. The correction factors due to precautionary motives are $\Delta_{B U}=11.9 \%$ and $\Delta_{I U}=10.7 \%$. Thus, optimal consumption is 1,868 .

Given the role of volatility in the solutions proposed, the correction factors increase linearly with the variance of the shocks to the price process. Thus, precautionary saving increases at rate 0.5 with volatility.

Example 6.2 (Precautionary Saving and Shocks Persistence) Figure 6.1 shows the correction factors $\Delta_{B U}$ and $\Delta_{I U}$ for different levels of the AR(1) coefficient of the oil price process and 
the parameters of the baseline example. In this case $\psi$ ranges from 0.9 to 1 . When $\psi<1$ we use

the formulae described in the Appendix. In all these cases we disregard any income effects arising from volatility by directly applying the correction factors to the zero variance consumption.

The results show that precautionary saving increases sharply with the persistence of shocks. When $\psi$ is around 0.9, correction factors are almost one-tenth of what they are in the case of a random walk. Furthermore, this difference is clearly non-linear. When $\psi$ is around 0.95, correction factors are about one-fourth of what they are when $\psi=1$.

This key role for shock persistence in determining the importance of precautionary saving has been noted before (see, e.g., Skinner, 1988). It follows from the high sensitivity of wealth uncertainty to the degree of persistence in shocks, particularly in the neighborhood of a random walk.

Example 6.3 (Precautionary Saving and Financial Assets) Figure 6.2 shows the correction factors $\Delta_{B U}$ and $\Delta_{I U}$ for levels of initial financial assets $F_{0}$ and the parameters of the baseline example. We have scaled $F_{0}$ by initial production, so it ranges from -4 to 4 .

As expected, financial assets accumulation makes less important precautionary saving. Because a larger portion of future consumption is secure when a country has more financial assets, precautionary saving decreases with $F_{0}$. In the example at hand, the correction factors drop by almost one third when financial assets increase from zero to four years of income. A similar pattern arises if one assumes that $\psi=0.9$, although in this case correction factors are considerably smaller.

Example 6.4 (Precautionary Saving and Resource Duration) Figure 6.3 shows the correction factors $\Delta_{B U}$ and $\Delta_{I U}$ for different time horizons for resource exhaustion and the parameters of the baseline example. $T$ varies from 5 to 105.

The results show that the correction factors increase quickly with $T$ to stabilize around $T=40$. The opposite happens if $\psi=0.9$ (case not reported). The intuition for the result is the following. Given an extraction rate, a longer duration represents a higher initial reserve level of the resource. This, in turn, represents higher total wealth, and less initial financial assets relative to total wealth. Thus, a longer duration produces an effect that is similar to having less financial assets. When $\psi<1$, a longer duration has two effects. One the one hand, it produces the same effect of reducing the share of financial assets in total wealth. On the other hand, because $\psi<1$, income that is very far in the future is almost secure income, having the same effect of a higher $F_{0}$. Figure 6.4 shows the correction factors for different $T$ assuming the "intermediate" case $\psi=0.99$. In this case the correction factors increase with $T$ between 10 and 20-25 and decrease thereafter.

In deriving precautionary saving correction factors we have so far assumed that there is only one source of income, namely oil production. A more realistic representation of oil exporting countries should incorporate natural gas extraction. In order to do so we assume that the price of gas is linear 
in the price of oil, that the price of oil follows a geometric random walk, and that both natural resources have their particular and known extraction path. In Proposition B.4 in the Appendix we derive expressions for the correction factors in this case. Based on these expressions one can show that having a second income source related to oil prices produces relatively minor changes in the correction factors.

\subsection{Adjustment Costs}

When adjustment costs are present, optimal consumption may not be equal to frictionless optimal consumption. Adjusting per capita government expenditures may have welfare consequences that go beyond those captured by standard utility functions. A drastic reduction in government expenditure may lead to political instability, discouraging investment and reducing future growth. A sudden increase in government expenditure may deteriorate the quality of management of government projects because of the lack of adequate supervision. It may also increase the costs of new projects because of bottlenecks in the supply of some inputs. In this section we analyze the effects of a specific form of adjustment costs, namely quadratic costs.

\subsubsection{Quadratic Adjustment Costs}

In order to derive practical implications from the existence of adjustment costs we study an approximation to the standard consumption problem (without income uncertainty) augmented with quadratic adjustment costs. In particular, assume that the problem with adjustment costs is represented by the following problem:

$$
\max _{c_{t}} \sum_{t \geq 0} \beta^{t}(1+n)^{t}\left\{\frac{c_{t}^{1-\rho}}{1-\rho}-k\left(l_{t}-l_{t-1}\right)^{2},\right\}
$$

subject to the budget constraint

$$
\sum_{t \geq 0} R^{-t} C_{t}=\mathcal{W}_{0}
$$

where $l_{t}$ is the $\log$ of the optimal level of per capita consumption in period $t$ and $k$ captures the importance of adjustment costs. Asymmetric adjustment costs can be incorporated by considering two possible values for $k$, one for consumption reductions $\left(k^{-}\right)$and one for consumption increases $\left(k^{+}\right)$.

Proposition C.1 in the Appendix shows that this problem can be approximated by solving

$$
\min _{l_{t}} \sum_{t \geq 0} \tilde{\beta}^{t}\left[\left(l_{t}-l^{*}\right)^{2}+\tilde{k}\left(l_{t}-l_{t-1}\right)^{2}\right],
$$

subject to no budget constraint, with

$$
\tilde{k}=\frac{2 k}{\rho\left[c^{*}\right]^{1-\rho}},
$$


where $c^{*}$ denotes the solution to the problem above when $k=0$ (see Proposition A.1) and $l^{*}=\log c^{*}$.

The second term in (32) captures the costs of adjusting while the first term corresponds to the welfare costs associated with deviating from the optimal expenditure level in the absence of adjustment costs.

As $k$, the constant $\tilde{k}$ can take two values, one for expenditure reductions, $\tilde{k}^{-}$, and another for expenditure increases, $\tilde{k}^{+}$.

Proposition C.2 in the Appendix shows that there exist constants $\alpha^{-}$and $\alpha^{+}$, both between zero and one, such that a good approximation for the logarithm of optimal consumption at time 0 incorporating adjustment costs, $l_{0}$, consists of adjusting partially toward $l^{*} \equiv \log c^{*}$. Thus:

$$
l_{0}-l_{-1}=\alpha\left(l^{*}-l_{-1}\right)
$$

where $\alpha$ can take two values, one if consumption increases $\left(\alpha^{+}\right)$and another when it decreases $\left(\alpha^{-}\right)$. The constants $\alpha^{+}$and $\alpha^{-}$are decreasing functions of $\tilde{k}^{+}$and $\tilde{k}^{-}$. The fraction of adjustment prescribed is larger when adjustment costs matter less. The adjustment speed also increases with $\rho$, since larger values of $\rho$ imply a smaller elasticity of substitution of consumption over time and therefore a stronger incentive to smooth expenditure.

\subsubsection{Eliciting Adjustment Costs}

A key parameter in determining the velocity of the adjustment process is the size of adjustment costs. In Proposition C.3 in the Appendix we show that if a policymaker is indifferent between

- the adjustment cost associated this period with an increase in per capita expenditure of $100 \times s_{a}$ percent

and

- the welfare improvement, in the absence of adjustment costs, associated with a $100 \times s_{n a}$ percent increase in per capita expenditure

then her value of $\tilde{k}$ is given by

$$
\tilde{k}^{+} \simeq \frac{2 s_{n a}}{\rho s_{a}^{2}} .
$$

A similar comparison, with a decrease in per capita expenditure in the first statement, leads to an analogous expression for $\tilde{k}^{-36}$

It is recommended that the value of $s_{n a}$ in the exercise described above be chosen neither too large (because the approximations involved become less precise) nor too small (because it is harder to make the comparison that is required). Suggested values are in the range from 0.05 to 0.20 .

\footnotetext{
${ }^{36}$ The question in the second statement continues being posed in terms of an increase in per-capita expenditure.
} 


\subsubsection{Examples}

Example 6.5 (Adjustment Costs) Figure 6.5 shows how $\alpha$ varies with $s_{n a}$ when $s_{a}$ is set at 0.20. The remaining parameter values are $n=0, \beta=1 / 1.05$ and $\rho=3$. For an $s_{n a}$ of 0.04 , the recommended partial adjustment is approximately $70 \%$. For an $s_{n a}$ of 0.40 , this value falls to $40 \%$.

Partial adjustment rates are almost insensitive to population growth rates. For instance, if $s_{n a}=0.04$ in this example, changing the population growth rate from $n=0$ to $n=0.04$ decreases the partial adjustment from 70 to $69 \%$. Variations of $\beta$ within a reasonable range also have a negligible impact.

Changes in the coefficient of risk aversion have a larger impact. Figure 6.6 shows how $\alpha$ varies with $\rho$. Considering $\rho=1$ instead of $\rho=3$ decreases the adjustment coefficient from 70 to $50 \%$.

\section{$7 \quad$ Stabilization Funds}

A stabilization fund is an asset accumulation account that has the objective of stabilizing a particular variable such as government spending. For this purpose, stabilization funds have a set of rules defining when income should be saved or spent, raising or decreasing the amount of resources at the fund correspondingly.

As mentioned in section 2, a correctly defined stabilization fund should result in a consumption (expenditure) pattern closely related to the optimal solution of the problem at hand. The rules should be such that, in combination with other sources of fiscal saving and credit, they implement the optimal fiscal strategy. This puts important restrictions on fiscal policy decisions apparently unrelated to the commodity under consideration (oil and gas in this case). The reason is simple: if the government undoes what the stabilization recommends, the country will not get the benefits from the (optimal) fiscal strategy. And since money is fungible, the temptation to undo the restrictions on expenditures imposed by the stabilization fund will often be large. For instance, if expenditures out of oil wealth are stabilized completely, but fiscal expenditures continue to follow a pattern that is positively correlated with oil prices (e.g., due to procyclical access to financing in the international capital market), there will be no welfare gain from having a fund. The objective, at the end, is to stabilize expenditure, not a particular form of income. Thus, changes in the stabilization fund should represent the sum of all government incomes and expenditures, that is, the overall net fiscal asset position.

Stabilization funds in commodity producing countries are usually based on a price contingent rule: the fund accumulates resources so long as the current commodity price is above certain threshold and spends if it is below a second threshold. These thresholds are preannounced and usually follow a simple formula, such as the average of the last $x$ years plus/minus a constant. The simplicity of this type of fund is very appealing. However it also imposes a very rigid structure 
which often leads to a solution far from optimal. ${ }^{37}$ Behind this type of rule is the notion that policymakers are able to distinguish transitory from permanent price shocks. Given the evidence revisited in section 5 , this clearly is a very strong assumption.

There are a few studies that have designed optimal stabilization funds using numerical procedures and the POIM as the benchmark problem. For example, Arrau and Claessens (1991), Kletzer, Newbery and Wright (1990), and the collection of papers in Engel and Meller (1993) design optimal funds under alternative assumptions. However, extending the POIM to incorporate precautionary motives may have unappealing consequences, since this model ignores the path of private income, and therefore its correlation with oil income. In deriving the approximation for precautionary saving presented in this paper we have assumed that this correlation is zero (private income is constant). This clearly is a strong assumption that should be relaxed in future research. ${ }^{38}$

To illustrate this point we refer to an example discussed in section 4.2 in which oil and non-oil income were assumed to be perfectly negatively correlated. The precautionary motive suggests that the government should, on average, spend less in every period than it would in the certaintyequivalence case. Yet these additional savings serve no purpose in this case, since there is no uncertainty in total income. In general, when private sector income is ignored, as in the POIM, precautionary saving could differ significantly from what they would be if uncertainty in total income were considered.

The stabilization fund that follows the set of prescriptions derived in this paper is not different from an otherwise standard stabilization fund used in several countries. The only key difference is that the set of rules is relatively more complex, which allows for the implicit solution to be closer to the optimal one. In principle, the stabilization fund in this model corresponds to financial assets $F_{t}$, and the set of rules may include intergenerational distribution, budget and income uncertainty and adjustment costs. Thus, if fiscal policy follows the strategy we recommend here, it will implicitly act as a stabilization fund. Of course, this fund could be explicitly setup, easing transparency and accountability. The rules for operating the fund will be the counterpart of the proposed fiscal strategy.

One important issue regarding actual implementation of the optimal fiscal strategy is the treatment of fiscal investment. The model presented here does not include an explicit role for investment and assumes that all positive NPV projects are developed (probably by the private sector). However, at the same time, we have excluded any secondary source of credit for the government in order to obtain the expected results from the proposed fiscal strategy. In this setup the results of the model can be associated to the maximum non-oil sector deficit that should be financed by

\footnotetext{
${ }^{37}$ For a criticism of the Chilean Copper Stabilization Fund along these lines see Basch and Engel 1993).

${ }^{38}$ The CNM is an attempt to incorporate non-oil income into the analysis, but it does so without considering the effects of uncertainty.
} 
surpluses in the oil sector. ${ }^{39}$ Furthermore, all saved resources (the stabilization fund itself) are kept in international liquid assets.

A second interpretation, equally valid from a theoretical perspective, is to consider that what the fiscal sector saves can be denominated either in international or domestic assets. In this case, $F_{t}$ will include both external resources and the stock of investment. If money is invested in profitable investment projects, marginal projects will yield a risk-adjusted rate of return equal to the international interest rate. Furthermore, in this case the results of the model should be thought of as the maximum consumption financed with oil revenues (equivalently, the maximum current non oil fiscal deficit, excluding investment).

It is also possible to design simultaneous stabilization funds, each one representing different saving motives. For example, following the issues studied in this paper, one could implement an intergenerational distribution fund, a precautionary saving fund, and an adjustment cost fund. Each fund could obey its specific saving rule, facilitating transparency. In general, both the intergenerational and precautionary fund will have positive assets, whereas the adjustment cost could have negative average assets. ${ }^{40}$

Yet there are important shortcomings of setting up simultaneous funds for this arrangement may jeopardize the overall fiscal strategy. For example, having a large positive amount in a particular fund and negative in others may generate wrong incentives in the political process.

\section{Concluding Remarks}

This paper has presented a set of rules for fiscal policy in oil producing countries incorporating three different issues: intergenerational distribution of oil wealth, optimal saving due to precautionary behavior, and speed of adjustment in the presence of adjustment costs. Instead of using complex numerical procedures, the paper derives closed-form solutions that approximate the optimal solution. Although actual optimal policy prescriptions are unknown, numerical procedures are capable of solving particular problems using intensive computer resources. However, these procedures are seldom used in practice by policymakers. Our approach has obvious advantages regarding transparency and implementation possibilities. Indeed, the set of prescriptions can be programmed in a spreadsheet and the results are known in real time.

The proposed prescriptions are calculated as approximations to the optimal solution using as starting point certainty equivalence, i.e., when the permanent oil income (POI) solution is the appropriate one, and the assumption that risk will be diversified away one period ahead. The proposed solutions can be thought of as a set of corrections to the POI solution that brings this

\footnotetext{
${ }^{39}$ Excluding oil extraction costs.

${ }^{40}$ For example, if negative adjustment costs are larger than positive adjustment costs.
} 
particular result closer to the optimal one. Of course, because they are approximations, they do not represent the optimal solution itself. Our current research is intended to evaluate how accurate are these proposed approximations, both the expansion around the certainty equivalence solution and the assumption of one-period-ahead diversification.

The paper has derived fiscal prescriptions both under the assumption that the oil price follows a geometric random walk process and a $\mathrm{AR}(1)$ process (in logs). However, the evidence revisited and new econometric evidence provided show that the geometric random walk assumption appears to be a more sensible representation. Yet it should be stressed that the framework we developed makes use of this assumption only partially. In the proposed setup, budget uncertainty allows us to include next year expected future price (more precisely, its mean and variance) which could be different from the actual current price. The random walk assumption is binding only two periods into the future.

Another important assumption behind the approach followed here to study the effects of uncertainty is that the POIM is an adequate description of the problem faced by the government. This is equivalent to assume that non-oil income is uncorrelated with oil (and gas) income. Future research should incorporate the possibility of a non-zero correlation between both types of income.

For simplicity, the proposed fiscal strategy was developed assuming an annual frequency, since we made the implicit assumption that the government could not revise the budget during the budget year. $^{41}$ This assumption can be easily relaxed reinterpreting the data frequency conveniently. Furthermore, without changing frequency, the model could be used during the current fiscal year if new information becomes available and the political process allows for adjustments in the budget. Yet such an exercise would necessarily have to be of the once-and-for-all type, since recurrent revisions would modify the model (or, at least, the appropriate data frequency).

Finally, the proposed approach has implicit a stabilization fund which could be explicitly setup for transparency and accountability purposes. There are two key ingredients for this fund to work properly. First, it should follow a set of accumulation rules that implement the proposed fiscal strategy. And second, it imposes strong restrictions to other forms of government financing so that what the fund accumulates actually reflects changes in the net fiscal asset position.

\footnotetext{
${ }^{41}$ The are good political economy arguments to maintain this procedure. In particular, there could be important asymmetries in the way the political process reacts to positive and negative shocks.
} 


\section{References}

[1] Alier, M., and M. Kaufmann, "Nonrenewable Resources: A Case for Persistent Fiscal Surpluses," IMF Working Paper 99/44, April 1999.

[2] Arrau, P., and S. Classens, "Commodity Stabilization Funds," mimeo, World Bank, 1991.

[3] Barro, R., "Are Government Bonds Net Wealth?," Journal of Political Economy, 82 No. 6, 1095-1117, 1974.

[4] Barro, R., "On the Determination of the Public Debt," Journal of Political Economy, 85 No. 5, 940-971, 1979.

[5] Bessembinder, H., "Mean Reversion in Equilibrium Asset Prices: Evidendence from the Futures Term Structure," Journal of Finance, 50 No. 1, 361-375, 1995.

[6] Caballero, R., "Consumption Puzzles and Precautionary Savings, Journal of Monetary Economics, 25 No. 1, 113-136, 1990.

[7] Carrol, C., "The Buffer-Stock Theory of Saving: Some Macroeconomic Evidence," Brookings Papers on Economic Activity, No. 2, 61-156, 1992.

[8] Deaton, A., "Saving and Liquidity Constraints," Econometrica, 59 No. 5, 1221-1248, 1991.

[9] Engel, E., and P. Meller, External Shocks and Stabilization Mechsnisms, Washington, D.C.: Inter-American Development Bank and Johns Hopkins University Press, 1993.

[10] Fasano, U., "Intergenerational Economic Equity and Fiscal Sustainability with Exhaustible Resoureces - the Case of Qatar", personal communication, October 11, 1999.

[11] Flavin, M., "The Adjustment of Consumption to Changing Expectations about Future Income," Journal of Political Economy, 89 No. 5 , 974-1009, 1981.

[12] Friedman, M., A Theory of the Consumption Function, Princeton: Princeton University Press, 1957.

[13] Hamilton, J.D., Time Series Analysis, Princeton: Princeton University Press, 1994.

[14] Kimball, M., "Precautionary saving in the small and in the large," Econometrica, 58, 53-73, 1990.

[15] Kletzer, K., D. Newbery and B. Wright, "Alternative Instruments for Smoothing Consumption of Primary Commodity Exporters," Working Paper Series 558, International Economics Department, World Bank, December 1990. 
[16] Leland, H.E., "Saving and Uncertainty: The Precautionary Demand for Saving," Quarterly Journal of Economics, 82 No. 2, 465-473, 1968.

[17] Liuksila, C., A. García and S. Bassett, "Fiscal Policy Sustainability in Oil-Producing Countries", IMF Working Paper 94/137, November 1994.

[18] Michael, P., A.R. Nobay and D. Peel, "Transactions Costs and Nonlinear Adjustment in Real Exchange Rates: An Empirical Investigation," Journal of Political Economy, 105 No. 4, 862$879,1997$.

[19] Perron, P., "The Great Crash, the Oil Price Shock, and the Unit Root Hypothesis," Econometrica, 57 No. 6, 1361-1401, 1989.

[20] Pindyck, R., "The Long-Run Evolution of Energy Prices," Energy Jounral, 20 No. 2, 1-27, 1999.

[21] Powell, A., "The Costs of Commodity Price Uncertainty," mimeo, Nuffield College, Oxford, 1990.

[22] Rotemberg, J., "Monopolistic Price Adjustment and Aggregate Output," Review of Economic Studies, 49, 517-531, 1982.

[23] Schwartz, E., "The Stochastic Behavior of Commodity Prices: Implications for Valuation and Hedging," Journal of Finance, 52 No. 3, 923-973, 1997.

[24] Skinner, J., "Risky Income, Life Cycle Consumption, and Precautionary Savings," Journal of Monetary Economics, 22 No. 2, 237-255, 1988.

[25] Videgaray, L. "The Fiscal Response to Oil Shocks," Unpublished PhD Dissertation, Massachusetts Institute of Technology, 1998.

[26] Zeldes, S., "Consumption and Liquidity Constraints: An Empirical Investigation," Journal of Political Economy, 97 No. 2, 305-346, 1989. 


\section{Appendices}

\section{A Benchmark and Conditionally Normative Models}

Lemma A.1 Maximizing the felicity function

$$
u\left(c_{P}, c_{G}\right)=\left(\frac{c_{P}^{1-\gamma}}{1-\gamma}+k \frac{c_{G}^{1-\gamma}}{1-\gamma}\right)^{1 /(1-\gamma)}
$$

subject to the budget constraint $c_{P}+c_{G}=c$ yields

$$
c_{P}=\frac{1}{1+k^{1 / \gamma}} c \quad \text { and } \quad c_{G}=\frac{k^{1 / \gamma}}{1+k^{1 / \gamma}} c .
$$

Moreover, the felicity function, evaluated at the optimum, is given by:

$$
u\left(c_{P}, c_{G}\right)=\left(\frac{\left(1+k^{1 / \gamma}\right)^{\gamma}}{1-\gamma}\right)^{1 /(1-\gamma)} c .
$$

Proof Straightforward calculus.

Lemma A.2 Solving the problem

$$
\max _{c_{G, t}, c_{P, t}} \frac{1}{1-\rho} \sum_{t \geq 0} \beta^{t}(1+n)^{t} u_{t}^{1-\rho}
$$

subject to the intertemporal budget constraint:

$$
\sum_{t \geq 0} R^{-t}\left[C_{G, t}+C_{P, t}\right]=\mathcal{W}_{0}
$$

with

$$
u_{t}=\left(\frac{c_{P, t}^{1-\gamma}}{1-\gamma}+k \frac{c_{G, t}^{1-\gamma}}{1-\gamma}\right)^{1 /(1-\gamma)}
$$

and $C_{j, t}=c_{j, t} N_{t}(j=C, G), N_{t}=(1+n)^{t}$, is equivalent to solving

$$
\max _{c_{t}} \frac{1}{1-\rho} \sum_{t \geq 0} \beta^{t}(1+n)^{t} c_{t}^{1-\rho}
$$

subject to the intertemporal budget constraint:

$$
\sum_{t \geq 0} R^{-t} C_{t}=\mathcal{W}_{0}
$$

where $C_{t}=C_{G, t}+C_{P, t}, c_{t}=C_{t} / N_{t}$. 
Proof From Lemma 1, the optimal choices of $c_{P, t}$ and $c_{G, t}$ must satisfy

$$
u\left(c_{P, t}, c_{G, t}\right)=\left(\frac{\left(1+k^{1 / \gamma}\right)^{\gamma}}{1-\gamma}\right)^{1 /(1-\gamma)} c_{t} .
$$

Substituting this expression for $u_{t}$ in (33) completes the proof.

Proposition A.1 Consider the intertemporal consumption allocation problem

$$
\max _{c_{t}} \frac{1}{1-\rho} \sum_{t \geq 0} \beta^{t}(1+n)^{t} c_{t}^{1-\rho}
$$

subject to the intertemporal dynamic budget constraint

$$
F_{t+1}=R\left[F_{t}+Y_{t}-C_{t}\right]
$$

where $C_{t}=c_{t} N_{t}, N_{t}=(1+n)^{t}, Y_{t}=Y_{P, t}+Y_{G, t}$, and $N_{0}=1$. Initial assets $\left(F_{0}\right)$ and the complete future stream of income, $Y_{0}, Y_{1}, Y_{2}, \ldots$ are known at time 0 .

Then optimal per capita consumption at time 0 is

$$
c_{0}=(1-\tilde{\alpha}) \mathcal{W}_{0}
$$

and the optimal consumption path satisfies

$$
\begin{aligned}
c_{t+1} & =[\beta R]^{1 / \rho} c_{t}, \\
C_{t+1} & =\alpha C_{t},
\end{aligned}
$$

where $\alpha=(1+n)[\beta R]^{1 / \rho} ; \tilde{\alpha}=\alpha / R$, and

$$
\mathcal{W}_{0} \equiv F_{0}+\sum_{s \geq 0} R^{-s}\left[Y_{G, s}+Y_{P, s}\right]
$$

Furthermore, the period t current account of this economy is given by

$$
C A_{t}=\left[2-\frac{1}{R}\right]\left(Y_{t}-C_{t}\right)+\left[1-\frac{1}{R}\right] F_{t} .
$$

Proof We first derive the slope of the consumption path and then the initial consumption level. Using $N_{t}=(1+n)^{t} N_{0}$ and $C_{t}=c_{t} N_{t}$ it is possible to rewrite the objective function as

$$
\max _{C_{t}} \frac{1}{(1-\rho) N_{0}^{1-\rho}} \sum_{t \geq 1}\left[\beta(1+n)^{\rho}\right]^{t} C_{t}^{1-\rho} .
$$

Using the dynamic budget constraint $F_{t+1}=R\left[F_{t}+Y_{t}-C_{t}\right]$ the problem becomes

$$
\max _{F_{t}} \frac{1}{(1-\rho) N_{0}^{1-\rho}} \sum_{t \geq 0}\left[\beta(1+n)^{\rho}\right]^{t}\left[F_{t}+Y_{t}-\frac{F_{t+1}}{R}\right]^{1-\rho} .
$$


The FOC for $F_{t}$ is:

$$
\left[\beta(1+n)^{\rho}\right]^{t}(1-\rho)\left[F_{t}+Y_{t}-\frac{F_{t+1}}{R}\right]^{-\rho}-\left[\beta(1+n)^{\rho}\right]^{t-1}(1-\rho)\left[F_{t-1}+Y_{t-1}-\frac{F_{t}}{R}\right]^{-\rho} \frac{1}{R}=0,
$$

which leads to (36). Dividing both sides of $(36)$ by $N_{t+1}=(1+n)^{t+1}$ yields (35).

The initial consumption level is found substituting the slope of the consumption path in the budget constraint. Successively replacing financial assets $F_{s}$ in the dynamic budget constraint for period $s$ and assuming that $\lim _{t \rightarrow \infty} R^{-t} F_{t}=0$ (no Ponzi or sustainability condition) one gets the standard present value budget constraint:

$$
\mathcal{W}_{0} \equiv F_{0}+\sum_{s \geq 0} R^{-s} Y_{s}=\sum_{s \geq 0} R^{-s} C_{s}
$$

Using (34) recursively leads to $C_{t}=\alpha^{t} C_{0}$, which we substitute in the present value budget constraint to obtain

$$
\mathcal{W}_{0}=\sum_{s \geq 0} \tilde{\alpha}^{s} C_{0}
$$

which implies that

$$
C_{0}=c_{0}=(1-\tilde{\alpha}) \mathcal{W}_{0}
$$

Lastly, by definition, the current account is the difference between income, which equals domestic production plus interests earned abroad, and expenditures, which equals total consumption. Earned interest accrues at the end of the period. Thus,

$$
C A_{t}=Y_{t}+\frac{R-1}{R}\left[W_{t}+Y_{t}-C_{t}\right]-C_{t},
$$

which after rearrangement yields (37).

Proposition A.2 Assume that there is no uncertainty, no bequest motive and $\beta R=1$. Also assume that the solution under the Benchmark Model leaves at least one generation worse off than it would be in the absence of oil wealth (and redistributive policies). ${ }^{42}$ Then the consumption path that implements the CNM obtains from the following algorithm:

1. Order the generations according to their utility under the assumption that oil reserves are zero, that is, that the only source of income is private. ${ }^{43}$ In what follows, generation 1 is the poorest generation, generation 2 the second poorest, and so on.

2. Set $k=1$.

\footnotetext{
${ }^{42}$ Otherwise the solution to the CNM is equal to the solution to the BM, since the additional constraint imposed by the CNM is not binding. That is, the solution to the CNM differs from that for the BM either if non oil income of future generations grows without limit, or if oil wealth is not enough to raise every generation's income above the income of the richest-in the absence of oil wealth-generation.

${ }^{43}$ Since there is no bequest motive and no uncertainty, there will be no intergenerational saving.
} 
3. Use oil wealth to raise the income of generation $k$ until it equals that of generation $(k+1)$ or until it is exhausted, whichever happens first.

4. If 3 does not exhaust the oil wealth, increase $k$ by 1 and return to 3. Otherwise, the resulting distribution of oil wealth solves the CNM.

Proof The algorithm ends because we assumed that the solution to the BM violates the constraints of the CNM. The remainder of the proof is straightforward.

\section{B Precautionary saving}

The following results consider the setup described in section 6.1.1.

Lemma B.1 Denote by $c_{0}\left(\sigma_{0}^{2}, \sigma_{v}^{2} ; F_{0}, \mu_{0}\right)$ the solution for optimal per capita consumption as a function of initial financial assets and parameters characterizing the distribution of future income. In what follows $F_{0}$ and $\mu_{0}$ remain fixed and are therefore omitted. Assuming $c_{0}\left(\sigma_{0}^{2}, \sigma_{v}^{2}\right)$ has continuous second order partial derivatives, we have that

$$
c_{0}\left(\sigma_{0}^{2}, \sigma_{v}^{2}\right)=\left[1-\Delta_{B U}-\Delta_{I U}\right] c_{0}(0,0)+\mathcal{O}\left(\sigma^{4}\right),
$$

with

$$
\begin{aligned}
\Delta_{B U} & =-\frac{c^{1}(0,0)}{c_{0}(0,0)} \sigma_{0}^{2}, \\
\Delta_{I U} & =-\frac{c^{2}(0,0)}{c_{0}(0,0)} \sigma_{v}^{2} .
\end{aligned}
$$

Where the superscripts denote derivatives with respect to argument $j(j=1,2), \sigma=\max \left(\sigma_{v}, \sigma_{0}\right)$, and $\mathcal{O}\left(\sigma^{4}\right)$ denotes a term of order $\sigma^{4}$.

Proof By continuous second order partial derivatives we mean that $c_{0}^{11}, c_{0}^{22}$ and $c_{0}^{12}$ are well defined and continuous. The result then follows from taking a first order Taylor expansion of $c_{0}\left(\sigma_{0}^{2}, \sigma_{v}^{2}\right)$ around $(0,0)$.

Corollary B.1 Assume that an increase in uncertainty (that is, either an increase in $\sigma_{0}$ or $\sigma_{v}$ ) does not affect initial wealth, ${ }^{44}$ so that $c_{0}^{C E}\left(\sigma_{0}^{2}, \sigma_{v}^{2}\right)=c_{0}^{C E}(0,0)$, where $c_{0}^{C E}$ denotes optimal per capita consumption under certainty equivalence and the arguments are the same as in the preceding proposition. Then

$$
c_{0}\left(\sigma_{0}^{2}, \sigma_{v}^{2}\right)=\left[1-\Delta_{B U}-\Delta_{I U}\right] c_{0}^{C E}\left(\sigma_{0}^{2}, \sigma_{v}^{2}\right)+\mathcal{O}\left(\sigma^{4}\right),
$$

with $\Delta_{B U}, \Delta_{I U}$ and $\mathcal{O}\left(\sigma^{4}\right)$ defined above.

\footnotetext{
${ }^{44}$ This holds, for example, when the price of oil follows a geometric random walk with drift such that $\mathrm{E}_{t}\left[P_{t+1}\right]=P_{t}$.
} 
Proof Trivial.

Definition B.1 Given a stochastic process $Y_{t}, t=0,1,2, \ldots$ for income, we denote

$$
\varphi=\sum_{t=0}^{T-1} \beta^{t} Y_{t+1}
$$

Proposition B.1 For any stochastic income process $Y_{t}$ that is identically zero from period $T+1$ onwards:

$$
c_{0}(0,0)=\frac{r-n}{R N_{0}}\left\{F_{0}+\mu_{0}+\left.\beta \mathrm{E}_{0}[\varphi]\right|_{\sigma_{v}=\sigma_{0}=0}\right\} \text {. }
$$

We also have:

$$
c_{0}^{1}(0,0)=\left.\frac{\beta^{2}(r-n)}{N_{0}} \frac{\partial \mathrm{E}_{0}[\varphi]}{\partial \sigma_{0}^{2}}\right|_{\sigma_{v}=\sigma_{0}=0}-\left.\frac{(1+\rho) \beta(r-n)^{2}}{2(1+n) N_{0}^{2} c_{0}(0,0)} \frac{\partial \operatorname{Var}_{0}\left(Y_{0}+\beta \mathrm{E}_{1}[\varphi]\right)}{\partial \sigma_{0}^{2}}\right|_{\sigma_{v}=\sigma_{0}=0},
$$

where $\mathrm{E}_{0}$ and $\operatorname{Var}_{0}$ are with respect to the distribution of $Y_{0}$, assuming $\sigma_{v}=0$, and

$$
c_{0}^{2}(0,0)=\left.\frac{\beta^{2}(r-n)}{N_{0}} \frac{\partial \mathrm{E}_{0}[\varphi]}{\partial \sigma_{v}^{2}}\right|_{\sigma_{v}=\sigma_{0}=0}-\left.\frac{(1+\rho) \beta^{3}(r-n)^{2}}{2(1+n) N_{0}^{2} c_{0}(0,0)} \frac{\partial \operatorname{Var}_{0}\left(\mathrm{E}_{1}[\varphi]\right)}{\partial \sigma_{v}^{2}}\right|_{\sigma_{v}=\sigma_{0}=0},
$$

where $\mathrm{E}_{0}$ and $\operatorname{Var}_{0}$ are with respect to the distribution of $P_{1}$, conditional on $P_{0}$ and assuming $\sigma_{0}=0$.

Furthermore, under the additional assumption that certainty equivalent consumption does not vary with $\sigma_{0}^{2}$ and $\sigma_{v}^{2}$, the first terms on the right hand side of (43) and (44) are zero. ${ }^{45}$

Proof The derivation of (42) is straightforward. Since the derivations of (43) and (44) are similar, we only provide the latter. We may assume $\sigma_{0}=0$ for this derivation and proceed in the following 3 steps:

1. Since all income uncertainty is diversified in period 1, per capita consumption thereafter remains constant; we denote it by $\bar{c}\left(\sigma_{v}^{2}\right) \cdot{ }^{46}$ This allows us to express $\bar{c}\left(\sigma_{v}^{2}\right)$ as a function of $c_{0}\left(\sigma_{v}^{2}\right)$ and $\mathrm{E}_{1}[\varphi]$. Based on this expression we find $\mathrm{E}_{0}\left[c_{0}\left(\sigma_{v}^{2}\right)\right]$ and $\operatorname{Var}_{0}\left[c_{0}\left(\sigma_{v}^{2}\right)\right]$.

2. Implicitly differentiating (a Taylor expansion of) the standard first order condition we obtain an expression for $c_{0}^{2}(0,0)$ in terms of $\mathrm{E}_{0}\left[c_{0}\left(\sigma_{v}^{2}\right)\right]$ and $\operatorname{Var}\left[c_{0}\left(\sigma_{v}^{2}\right)\right]$ (and their derivatives).

3. Substituting in 2 the expressions derived in 1 concludes the proof.

\footnotetext{
${ }^{45}$ The first terms in (43) and (44) capture wealth effects associated with changes in $\sigma_{0}^{2}$ and $\sigma_{v}^{2}$, respectively. The second terms correspond to precautionary saving.

${ }^{46}$ Dependence on $\sigma_{0}$ is omitted since it is assumed equal to zero.
} 
Next we spell out the details. Since all income uncertainty is eliminated in period 1, optimal consumption at that point in time will be equal to certainty equivalent consumption, so that (42) implies that

$$
\bar{c}\left(\sigma_{v}^{2}\right) \equiv c_{1}=\frac{r-n}{R N_{1}}\left\{F_{1}+\mathrm{E}_{1}[\varphi]\right\} .
$$

Substituting the budget constraint (34) and rearranging terms leads to:

$$
\bar{c}\left(\sigma_{v}^{2}\right)=\frac{r-n}{1+n}\left[\frac{F_{0}+Y_{0}}{N_{0}}-c_{0}\left(\sigma_{v}^{2}\right)+\frac{1}{R N_{0}} \mathrm{E}_{1}[\varphi]\right] .
$$

It follows that:

$$
\begin{aligned}
\bar{\mu} & \equiv \mathrm{E}_{0}\left[\bar{c}\left(\sigma_{v}^{2}\right)\right]=\frac{r-n}{(1+n) N_{0}}\left[F_{0}+Y_{0}+\beta \mathrm{E}_{0}[\varphi]-N_{0} c_{0}\left(\sigma_{v}^{2}\right)\right] \\
\bar{\sigma}^{2} & \equiv \operatorname{Var}_{0}\left[\bar{c}\left(\sigma_{v}^{2}\right)\right]=\frac{(r-n)^{2}}{(1+n)^{2} N_{0}^{2}} \beta^{2} \operatorname{Var}_{0}\left(\mathrm{E}_{1}[\varphi]\right) .
\end{aligned}
$$

The usual Euler equation for this problem is:

$$
u^{\prime}\left(c_{0}\left(\sigma_{v}^{2}\right)\right)=\mathrm{E}_{0}\left[u^{\prime}\left(\bar{c}\left(\sigma_{v}^{2}\right)\right)\right],
$$

which, after taking a second order Taylor expansion on the right hand side around $\bar{\mu}\left(\sigma_{v}^{2}\right)$, becomes

$$
u^{\prime}\left(c_{0}\left(\sigma_{v}^{2}\right)\right) \simeq u^{\prime}\left(\bar{\mu}\left(\sigma_{v}^{2}\right)\right)+\frac{1}{2} u^{\prime \prime \prime}\left(\bar{\mu}\left(\sigma_{v}^{2}\right)\right) \bar{\sigma}^{2}\left(\sigma_{v}^{2}\right) .
$$

Implicitly differentiating the latter (approximate) identity with respect to $\sigma_{v}^{2}$, evaluating at $\sigma_{v}^{2}=0$ and noting that $\bar{\mu}(0)=c_{0}(0)$ and $\bar{\sigma}^{2}(0)=0$ leads to

$$
u^{\prime \prime}\left(c_{0}(0)\right) c_{0}^{1}(0) \simeq u^{\prime \prime}\left(c_{0}(0)\right) \bar{\mu}^{\prime}(0)+\frac{1}{2} u^{\prime \prime \prime}\left(c_{0}(0)\right) \frac{\partial \bar{\sigma}^{2}}{\partial \sigma_{v}^{2}}(0),
$$

where $\bar{\mu}^{\prime}$ and $\partial \bar{\sigma}^{2} / \partial \sigma_{v}^{2}$ denote the derivatives of $\bar{\mu}$ and $\bar{\sigma}^{2}$ with respect to $\sigma_{v}^{2}$. Substituting (45) and (46) in (47) and rearranging terms leads to (44).

Corollary B.2 Under the same assumptions (and notation) of the preceding proposition, in the case where certainty equivalent consumption does not depend on $\sigma_{0}^{2}$ and $\sigma_{v}^{2}$, we have:

$$
\begin{aligned}
\Delta_{B U} & =\left.\frac{1}{2}(1+\rho) \frac{\beta(r-n)^{2}}{(1+n) N_{0}^{2} c_{0}(0,0)^{2}} \frac{\partial \operatorname{Var}_{0}\left(Y_{0}+\mathrm{E}_{1}[\varphi]\right)}{\partial \sigma_{0}^{2}}\right|_{\sigma_{v}=\sigma_{0}=0} \sigma_{0}^{2} \\
\Delta_{I U} & =\left.\frac{1}{2}(1+\rho) \frac{\beta^{3}(r-n)^{2}}{(1+n) N_{0}^{2} c_{0}(0,0)^{2}} \frac{\partial \operatorname{Var}_{0}\left(Y_{0}+\mathrm{E}_{1}[\varphi]\right)}{\partial \sigma_{v}^{2}}\right|_{\sigma_{v}=\sigma_{0}=0} \sigma_{v}^{2}
\end{aligned}
$$


Proof Follows directly form (39), (40) and the preceding proposition.

Lemma B.2 Assume that $\log P_{t}$ follows a first order autoregressive process:

$$
\log P_{t}-\mu=\psi\left(\log P_{t-1}-\mu\right)+v_{t},
$$

with $-1<\psi \leq 1$ and the $v_{t}$ 's i.i.d. normal with zero mean and variance $\sigma_{v}^{2}$. Let $Q_{t}=Q_{0}(1+g)^{t}$, $t \leq T$ and $Y_{t}=P_{t} Q_{t}$.

Then

$$
\mathrm{E}_{1}\left[P_{t+1}\right]= \begin{cases}P_{1} \exp \left[\frac{1}{2} \sigma_{v}^{2} t\right] & \text { if } \psi=1, \\ P_{1} \exp \left[\left(1-\psi^{t}\right)\left(\mu-\log \left(P_{1}\right)\right)+\frac{1}{2} \sigma_{v}^{2} \frac{1-\psi^{2 t}}{1-\psi^{2}}\right] & \text { if } \psi<1 .\end{cases}
$$

We also have

$$
\mathrm{E}_{1}[\varphi]= \begin{cases}Y_{1} \frac{1-\left[\beta(1+g) \exp \frac{1}{2} \sigma_{v}^{2}\right]^{T}}{1-\left[\beta(1+g) \exp \frac{1}{2} \sigma_{v}^{2}\right]} & \text { if } \psi=1, \\ Y_{1} \sum_{t=0}^{T-1}[\beta(1+g)]^{t} \exp \left[\left(1-\psi^{t}\right)\left(\mu-\log \left(P_{1}\right)\right)+\frac{1}{2} \sigma_{v}^{2} \frac{1-\psi^{2 t}}{1-\psi^{2}}\right] & \text { if } \psi<1 .\end{cases}
$$

Proof Applying (50) recursively leads to

$$
\log \left(P_{t+1}\right)-\mu=\psi^{t}\left(\log \left(P_{1}\right)-\mu\right)+\psi^{t-1} v_{2}+\psi^{t-2} v_{3}+\ldots+v_{t+1} .
$$

Taking exponentials on both sides and then expectations, and using the assumption of independent $v$ 's, leads to

$$
\mathrm{E}_{1}\left[P_{t+1}\right]=\exp \left[\mu\left(1-\psi^{t}\right)+\psi^{t} \log \left(P_{1}\right)\right] \Pi_{i=1}^{t} \mathrm{E}\left[\exp \left(\psi^{t-i} v_{i+1}\right)\right]
$$

Using the well known expression for the moment generating function of a normal distribution, evaluating the resulting geometric sums and rearranging terms completes the the derivation of $\mathrm{E}_{1}\left[P_{t+1}\right]$. Deriving the expressions for $\mathrm{E}_{1}[\varphi]$ now is straightforward.

Lemma B.3 Let $v$ be a Normal random variable with zero mean and variance $\sigma^{2}$ and define $w=\sum_{i=1}^{n} c_{i} \exp \left[a_{i} v\right]$, where the $c_{i}$ 's and $a_{i}$ 's are constants. Then:

$$
\left.\frac{\partial \operatorname{Var}[w]}{\partial \sigma^{2}}\right|_{\sigma^{2}=0}=\left[\sum_{i=1}^{n} c_{i} a_{i}\right]^{2}
$$

Proof Using the moment generating function of a Normal random variable we obtain

$$
\begin{aligned}
\mathrm{E}[w] & =\sum_{i} c_{i} \exp \left[\frac{1}{2} a_{i}^{2} \sigma^{2}\right] \\
\mathrm{E}\left[w^{2}\right] & =\sum_{i} c_{i}^{2} \exp \left[2 a_{i}^{2} \sigma^{2}\right]+2 \sum_{i<j} c_{i} c_{j} \exp \left[\frac{1}{2}\left(a_{i}+a_{j}\right)^{2} \sigma^{2}\right] .
\end{aligned}
$$


It follows that

$$
\operatorname{Var}[w]=\sum_{i} c_{i}^{2}\left(e^{2 a_{i}^{2} \sigma^{2}}-e^{a_{i}^{2} \sigma^{2}}\right)+2 \sum_{i<j} c_{i} c_{j}\left(e^{\frac{1}{2}\left(a_{i}+a_{j}\right)^{2} \sigma^{2}}-e^{\frac{1}{2}\left(a_{i}^{2}+a_{j}^{2}\right) \sigma^{2}}\right)
$$

Differentiating the above expression with respect to $\sigma^{2}$ and evaluating at $\sigma^{2}=0$ leads to (52).

Proposition B.2 Assume that the logarithm of the price process follows follows a first order autoregressive process:

$$
\log P_{t}-\mu=\psi\left(\log P_{t-1}-\mu\right)+v_{t},
$$

with the $v_{t}$ 's i.i.d. normal with mean $\mu_{v}$ and variance $\sigma_{v}^{2}$. We ignore the income effect associated with changes in $\sigma_{0}$ and $\sigma_{v}$. The remainder of the setup is the same as in section 6.1.1.

Then, if $\psi=1$ the correction factors are given by:

$$
\begin{aligned}
\Delta_{B U} & =\frac{1}{2}(1+\rho) \frac{R}{(1+n)}\left\{1+\frac{1-\beta(1+g)}{1-\beta^{T+1}(1+g)^{T+1}}\left[\frac{F_{0}}{\mu_{0}}\right]\right\}^{-2} C V_{0}^{2}, \\
\Delta_{I U} & =\frac{1}{2}(1+\rho) \frac{\beta(1+g)^{2}}{(1+n)}\left\{\frac{1-\{\beta(1+g)\}^{T}}{[1-\beta(1+g)] \frac{F_{0}}{\mu_{0}}+1-\{\beta(1+g)\}^{T+1}}\right\}^{2} \sigma_{v}^{2},
\end{aligned}
$$

where $C V_{0}=\sigma_{0} / \mu_{0}$.

If $\psi<1$ the correction factors are given by:

$$
\begin{aligned}
\Delta_{B U} & \simeq \frac{1}{2}(1+\rho) \frac{R}{(1+n)}\left\{\frac{\sum_{s=0}^{T}[\beta \psi(1+g)]^{s} \exp \left[\left(1-\psi^{s}\right)\left(\mu-\log \mu_{P, 0}\right)\right]}{\frac{F_{0}}{\mu_{0}}+\sum_{s=0}^{T}[\beta(1+g)]^{s} \exp \left[\left(1-\psi^{s}\right)\left(\mu-\log \mu_{P, 0}\right)\right]}\right\}^{2} C V_{0}^{2}, \\
\Delta_{I U} & \simeq \frac{1}{2}(1+\rho) \frac{R}{(1+n) \psi^{2}}\left\{\frac{\sum_{t=1}^{T}[\beta \psi(1+g)]^{t} \exp \left[\left(1-\psi^{t}\right)\left(\mu-\log \mu_{P, 0}\right)\right]}{\frac{F_{0}}{\mu_{0}}+\sum_{s=0}^{T}[\beta(1+g)]^{s} \exp \left[\left(1-\psi^{s}\right)\left(\mu-\log \mu_{P, 0}\right)\right]}\right\}^{2} \sigma_{v}^{2} .
\end{aligned}
$$

Proof We derive (55), of which (53) is a particular case. ${ }^{47}$ The derivation of (54) and (56) is analogous. From (49) it follows that to derive (55)) it suffices to calculate $c_{0}(0,0)$ and $\partial \operatorname{Var}_{0}\left(\mathrm{E}_{1}[\varphi]\right) / \partial \sigma_{v}^{2}$ evaluated at $\sigma_{0}^{2}=\sigma_{v}^{2}=0$.

From (42) and a slight modification of (51), evaluated at $\sigma_{0}=\sigma_{v}=0$, we have:

$$
c_{0}(0,0)=\frac{r-n}{R N_{0}}\left\{F_{0}+\mu_{0}+\mu_{0} \sum_{t=0}^{T-1}[\beta(1+g)]^{t+1} e^{\left(1-\psi^{t+1}\right)\left(\mu-\log \left(P_{0}\right)\right)}\right\}
$$

and hence

$$
c_{0}(0,0)=\frac{r-n}{R N_{0}}\left\{F_{0}+\mu_{0} \sum_{s=0}^{T}[\beta(1+g)]^{s} e^{\left(1-\psi^{s}\right)\left(\mu-\log \left(P_{0}\right)\right)}\right\} .
$$

\footnotetext{
${ }^{47}$ Strictly speaking, L'Hopital's rule must be invoked to go from (55) to (53).
} 
Next we determine $\partial \operatorname{Var}_{0}\left(\mathrm{E}_{1}[\varphi]\right) / \partial \sigma_{v}^{2}$ evaluated at $\sigma_{v}^{2}=0$. Substituting $\psi\left(\log \left(P_{0}\right)-\mu\right)+v_{1}$ for $\log \left(P_{1}\right)-\mu$ in (51) leads to

$$
\operatorname{Var}_{0}\left(\mathrm{E}_{1}[\varphi]\right)=(1+g)^{2} Y_{0}^{2} \operatorname{Var}_{0}\left[\sum_{t=0}^{T-1} c_{t} e^{a_{t} v_{1}}\right]
$$

with

$$
\begin{aligned}
& c_{t}=[\beta(1+g)]^{t} e^{\left(1-\psi^{t+1}\right)\left(\mu-\log \left(P_{0}\right)\right)+\frac{1}{2} \sigma_{v}^{2} \frac{1-\psi^{2 t}}{1-\psi^{2}}}, \\
& a_{t}=\psi^{t} .
\end{aligned}
$$

It now follows from (52) that

$$
\left.\frac{\partial \operatorname{Var}_{0}\left(\mathrm{E}_{1}[\varphi]\right)}{\partial \sigma_{v}^{2}}\right|_{\sigma_{v}=\sigma_{0}=0}=(1+g)^{2} Y_{0}^{2}\left[\sum_{t=0}^{T-1}[\beta \psi(1+g)]^{t} \exp \left[\left(1-\psi^{t+1}\right)\left(\mu-\log \mu_{P, 0}\right)\right]\right]^{2} .
$$

Substituting (57) and (58) into (49) and rearranging terms completes the proof.

Proposition B.3 Assume the price of oil follows a geometric random walk with variance of innovations $\sigma_{v}^{2}$ and drift such that $\mathrm{E}_{t}\left[P_{t+1}\right]=P_{t} .{ }^{48}$ Then the expressions (53) and (54) are also valid in this case.

Proof Similar to that of the preceding proposition. The main difference ins that in this case the first term on the right hand side of (43) and (44) is not being ignored, since it is equal to zero.

Proposition B.4 Consider the setup described in section 6.1.1 with two income sources (oil and gas), with extraction rates $Q_{t}^{O}$ and $Q_{t}^{G}$, respectively. Assume that the price of oil, $P_{t}^{O}$, follows a geometric random walk with drift such that $\mathrm{E}_{t}\left[P_{t+1}^{O}\right]=P_{t}^{O}$ and the price of gas, $P_{t}^{G}$, satisfies $P_{t}^{G}=\alpha_{0}+\alpha_{1} P_{t}^{O}$. Then

$$
c_{0}(0,0)=\frac{r-n}{R N_{0}}\left\{F_{0}+\frac{1-\left[\beta\left(1+g^{O}\right)\right]^{T^{O}+1}}{1-\left[\beta\left(1+g^{O}\right)\right]} \mu_{0}^{O}+\frac{1-\left[\beta\left(1+g^{G}\right)\right]^{T^{G}+1}}{1-\left[\beta\left(1+g^{G}\right)\right]} \mu_{0}^{G}\right\},
$$

where $g^{O}$ and $g^{G}$ denote the growth rates of oil and gas extraction, $T^{O}$ and $T^{G}$ the period where oil and gas reserves are exhausted, and $\mu_{0}^{O}$ and $\mu_{0}^{G}$ oil and gas income estimated for year 0 .

We also have

$$
\left.\frac{\partial \operatorname{Var}_{0}\left(Y_{0}+\beta \mathrm{E}_{1}[\varphi]\right)}{\partial \sigma_{0}^{2}}\right|_{\sigma_{v}=\sigma_{0}=0}=\left\{f^{O} \frac{1-\left[\beta\left(1+g^{O}\right)\right]^{T^{O}+1}}{1-\beta\left(1+g^{O}\right)}+f^{G} \frac{1-\left[\beta\left(1+g^{G}\right)\right]^{T^{G}+1}}{1-\beta\left(1+g^{G}\right)}\right\}^{2}
$$

\footnotetext{
${ }^{48}$ This assumption, which is equivalent to having a drift equal to $-\frac{1}{2} \sigma_{v}^{2}$, ensures that changes in $\sigma_{0}$ and $\sigma_{v}$ induce no income effects.
} 
where $f^{O}=Q_{0}^{O} /\left(Q_{0}^{O}+\alpha_{1} Q_{0}^{G}\right), f^{G}=1-f^{O}$ and $\operatorname{Var}_{0}$ is with respect to the distribution of $Y_{0}$, assuming $\sigma_{v}=0$, and

$$
\left.\frac{\partial \operatorname{Var}_{0}\left(\mathrm{E}_{1}[\varphi]\right)}{\partial \sigma_{v}^{2}}\right|_{\sigma_{v}=\sigma_{0}=0}=\left\{Q_{1}^{O} \frac{1-\left[\beta\left(1+g^{O}\right)\right]^{T^{O}}}{1-\beta\left(1+g^{O}\right)}+\alpha_{1} Q_{1}^{G} \frac{1-\left[\beta\left(1+g^{G}\right)\right]^{T^{G}}}{1-\beta\left(1+g^{G}\right)}\right\}^{2}\left(P_{0}^{O}\right)^{2} .
$$

where $\operatorname{Var}_{0}$ is with respect to the distribution of $P_{1}$ conditional on $P_{0}$, assuming $\sigma_{0}=0$.

Expressions (60) and (61) can be used to calculate $c_{0}^{1}(0,0)$ and $c_{0}^{2}(0,0)$ so as to apply Corollary B.2 to find an approximation for $c_{0}\left(\sigma_{0}^{2}, \sigma_{v}^{2}\right)$.

Proof The derivation of (59) is similar to that of (42) because of linearity of the expectations operator. Since the proofs of (61) and (60) are similar, we only provide the latter.

Linearity of the expectations operator and (51) lead to

$$
\operatorname{Var}_{0}\left(Y_{0}+\beta \mathrm{E}_{1}[\varphi]\right)=\left\{Q_{0}^{O} \frac{1-\left[\beta\left(1+g^{O}\right)\right]^{T^{O}+1}}{1-\beta\left(1+g^{O}\right)}+\alpha_{1} Q_{0}^{G} \frac{1-\left[\beta\left(1+g^{G}\right)\right]^{T^{G}+1}}{1-\beta\left(1+g^{G}\right)}\right\}^{2} \sigma_{P, 0}^{2} .
$$

Since

$$
\begin{aligned}
\sigma_{0}^{2} & =\operatorname{Var}\left[Y_{0}\right] \\
& =\operatorname{Var}\left[P_{0}^{O} Q_{0}^{O}+\left(\alpha_{0}+\alpha_{1} P_{0}^{O}\right) Q_{0}^{G}\right] \\
& =\operatorname{Var}\left[P_{0}^{O} Q_{0}^{O}+\alpha_{1} P_{0}^{O} Q_{0}^{G}\right] \\
& =\left[Q_{0}^{O}+\alpha_{1} Q_{0}^{G}\right]^{2} \sigma_{P, 0}^{2},
\end{aligned}
$$

the expression obtained in (62) leads to

$$
\operatorname{Var}_{0}\left(Y_{0}+\beta \mathrm{E}_{1}[\varphi]\right)=\left\{f^{O} \frac{1-\left[\beta\left(1+g^{O}\right)\right]^{T^{O}+1}}{1-\beta\left(1+g^{O}\right)}+f^{G} \frac{1-\left[\beta\left(1+g^{G}\right)\right]^{T^{G}+1}}{1-\beta\left(1+g^{G}\right)}\right\}^{2} \sigma_{0}^{2} .
$$

Differentiating the latter identity with respect to $\sigma_{0}^{2}$ yields $(60)$.

\section{Adjustment Costs}

Proposition C.1 Consider the optimal consumption problem with certain income:

$$
\begin{aligned}
& \max _{c_{t}} \sum_{t \geq 0} \tilde{\beta}^{t}\left[u\left(c_{t}\right)-k\left(l_{t}-l_{t-1}\right)^{2}\right], \\
\text { s.t. } & \sum_{t \geq 0} \beta^{t} C_{t}=\mathcal{W}_{0},
\end{aligned}
$$

where $\beta$ denotes the subjective discount rate, which is assumed equal to the inverse of the gross interest rate $(R \beta=1)$, population in period $t$ is $N_{t}=(1+n)^{t}, \tilde{\beta}=\beta(1+n)<1, C_{t}$ denotes period 
$t$ consumption, $c_{t}=C_{t} / N_{t}, u(c)=c^{1-\rho} /(1-\rho)$ for $\rho>0, \rho \neq 1$ and $\log c$ for $\rho=1, l_{t}=\log \left(c_{t}\right)$ and $\mathcal{W}_{0}$ denotes initial wealth.

Denote by $c^{*}$ the solution the problem above when $k=0$ (see Proposition A.1) and let $l^{*}=\log c^{*}$. Then solving (64) subject to (65) is equivalent to solving

$$
\min _{l_{t}} \sum_{t \geq 0} \tilde{\beta}^{t}\left[\left(l_{t}-l^{*}\right)^{2}+\mathcal{O}\left(\left(l_{t}-l^{*}\right)^{3}\right)+\tilde{k}\left(l_{t}-l_{t-1}\right)^{2}\right],
$$

subject to no budget constraint, with

$$
\tilde{k}=\frac{2 k}{\rho\left[c^{*}\right]^{1-\rho}}
$$

Proof Taking a second order Taylor expansion around $c^{*}$ for $u\left(c_{t}\right)$ in (64) and noting that, due to the budget constraint (65), the term in the objective function that is linear in $c_{t}-c^{*}$ adds up to zero, we have that the problem is (approximately) equivalent to solving

$$
\max _{c_{t}} \sum_{t \geq 0} \tilde{\beta}^{t}\left[\frac{1}{2} u^{\prime \prime}\left(c^{*}\right)\left(c_{t}-c^{*}\right)^{2}-k\left(l_{t}-l_{t-1}\right)^{2}\right]
$$

subject to no budget constraint.

A second order Taylor expansion for $\exp \left[l_{t}\right]$ around $l^{*}$ yields:

$$
\begin{aligned}
c_{t}-c^{*} & =e^{l_{t}}-e^{l^{*}} \\
& \simeq c^{*}\left(l_{t}-l^{*}\right)\left[1+\frac{1}{2}\left(l_{t}-l^{*}\right)\right],
\end{aligned}
$$

so that

$$
\left(c_{t}-c^{*}\right)^{2} \simeq\left[c^{*}\right]^{2}\left(l_{t}-l^{*}\right)^{2} .
$$

Substituting this approximation in (68) leads to (66) and (67).

Proposition C.2 Given values of $l_{-1}$ and $l^{*}$ consider the problem

$$
\min _{l_{t}} \sum_{t \geq 0} \tilde{\beta}^{t}\left[\left(l_{t}-l^{*}\right)^{2}+\tilde{k}\left(l_{t}-l_{t-1}\right)^{2}\right],
$$

with $\tilde{\beta}<1$. Define

$$
\alpha=\frac{1-\tilde{k}(1-\tilde{\beta})+\sqrt{1+2 \tilde{k}(1+\tilde{\beta})+\tilde{k}^{2}(1-\tilde{\beta})^{2}}}{1+\tilde{k}(1+\tilde{\beta})+\sqrt{1+2 \tilde{k}(1+\tilde{\beta})+\tilde{k}^{2}(1-\tilde{\beta})^{2}}} .
$$

Then the optimal logarithm of per capita consumption in period $0, l_{0}$, is determined by

$$
l_{0}-l_{-1}=\alpha\left(l^{*}-l_{-1}\right) .
$$

We also have that $0<\alpha<1$, in fact:

$$
\frac{1}{\tilde{k}+1} \leq \alpha \leq \frac{\sqrt{1+4 \tilde{k}}-1}{2 \tilde{k}} .
$$


Proof This is a well known result, see, for example, Rotemberg (1982) for a considerably more general case. The lower and upper bounds for $\alpha$ in (72) follow from showing that $\alpha$ is increasing in $\tilde{\beta}$ and evaluating $\alpha$ at $\tilde{\beta}=0$ and $\tilde{\beta}=1$.

Corollary C.1 Since there is no income uncertainty, the two preceding propositions can be easily extended to the case of asymmetric quadratic adjustment costs, so that:

$$
\text { Cost of adjusting from } l_{-1} \text { to } l_{0}= \begin{cases}k^{+}\left(l_{t}-l_{t-1}\right)^{2}, & \text { if } l_{t}>l_{t-1}, \\ k^{-}\left(l_{t}-l_{t-1}\right)^{2}, & \text { if } l_{t}<l_{t-1} .\end{cases}
$$

Now there will be two values for $\tilde{k}, \tilde{k}^{+}$and $\tilde{k}^{-}$, depending on whether per capita consumption increases or decreases. Both of them can be obtained from an expression analogous to (67). The optimal policy continues being of partial adjustment, but the speed of adjustment now depends on whether per capita consumption increases $\left(\alpha^{+}\right)$or decreases $\left(\alpha^{-}\right)$. Expressions for $\alpha^{+}$and $\alpha^{-}$are obtained by substituting $\tilde{k}^{+}$and $\tilde{k}^{-}$in (70).

\section{Proof Straightforward.}

Proposition C.3 In the setting of the preceding corollary, being indifferent between

- the adjustment cost associated this period with an increase in per capita expenditure of $100 \times s_{a}$ percent

and

- the welfare improvement, in the absence of adjustment costs, associated with a $100 \times s_{n a}$ percent increase in per capita expenditure

implies that

$$
\tilde{k}^{+} \simeq \frac{2 s_{n a}}{\rho s_{a}^{2}} .
$$

A similar comparison, with a decrease in per capita expenditure in the first statement, leads to an analogous expression for $\tilde{k}^{-}$.

Proof The welfare loss associated with the first statement is equal to $k s_{a}^{2}$, where we are using the equivalence result in Proposition C.1.

Let $c>c_{0}$ denote the two per capita consumption levels mentioned in the second statement, and $l$ and $l_{0}$ their logarithms. Then

$$
\begin{aligned}
u(c)-u\left(c_{0}\right) & \simeq u^{\prime}\left(c_{0}\right)\left(c-c_{0}\right) \\
& =u^{\prime}\left(c_{0}\right)\left[e^{l}-e^{l_{0}}\right] \\
& \simeq u^{\prime}\left(c_{0}\right) e^{l_{0}}\left(l-l_{0}\right) \\
& =u^{\prime}\left(c_{0}\right) c_{0} s_{n a} .
\end{aligned}
$$


It follows that

$$
k s_{a}^{2} \simeq u^{\prime}\left(c_{0}\right) c_{0} s_{n a} .
$$

Using (67) to substitute $\tilde{k}$ for $k$ in the expression above (and, strictly speaking, assuming $c_{0}=c^{*}$ ) leads to (73). 【 
TABLE 5.1

ADF AND PP TESTS

\begin{tabular}{lccc}
\hline \hline & 1957.I-1999.II & 1974.I-1999.II & 1986.I-1999.II \\
\hline \hline ADF no trend & -1.77 & $-2.60^{*}$ & $-3.42^{* *}$ \\
ADF with trend & -1.69 & $-3.83^{* *}$ & $-3.52^{* * *}$ \\
PP no trend & -1.65 & -2.56 & $-3.93^{* * *}$ \\
PP with trend & -1.52 & $-4.57^{* * *}$ & $-4.25^{* * *}$ \\
\hline \hline
\end{tabular}

Note: ${ }^{*}, *$, and ${ }^{* * *}=$ significant at 10,5 , and $1 \%$ respectively.

TABLE 5.2

P-Values Non-Linear Adjustment Test

\begin{tabular}{lccc}
\hline \hline & 1957.I-1999.II & 1974.I-1999.II & 1986.I-1999.II \\
\hline \hline$d=1$ & $0.12(1)$ & $0.02(1)$ & $0.10(1)$ \\
$d=2$ & $0.56(1)$ & $0.14(1)$ & $0.19(2)$ \\
$d=3$ & $0.40(1)$ & $0.40(1)$ & $0.12(2)$ \\
\hline \hline
\end{tabular}

Note: In parenthesis the value of $k$ that yields white noise. 
TABLE 5.3

One AND Two Year Ahead Forecast RMSE

\begin{tabular}{rlrrrr}
\hline \hline & & \multicolumn{2}{c}{ Short sample } & \multicolumn{2}{c}{ Long sample } \\
& & 1 year & 2 years & 1 year & 2 years \\
\hline \hline 1 & Random walk, no drift & $15.6 \%$ & $20.4 \%$ & $15.6 \%$ & $20.4 \%$ \\
2 & Random walk, with drift & $17.2 \%$ & $20.3 \%$ & $16.0 \%$ & $22.5 \%$ \\
3 & ARIMA $(2,1,2)$ & $17.0 \%$ & $21.8 \%$ & $12.7 \%$ & $13.3 \%$ \\
4 & ARIMA $(2,1,2)$, with dummy & $13.8 \%$ & $16.2 \%$ & $16.3 \%$ & $23.6 \%$ \\
5 & AR(1) & $18.2 \%$ & $21.6 \%$ & $25.5 \%$ & $21.6 \%$ \\
6 & BN Decomposition & $15.0 \%$ & $21.0 \%$ & $17.1 \%$ & $21.6 \%$ \\
7 & Kalman $\psi_{t}$ RW, no trend & $22.7 \%$ & $34.6 \%$ & $15.8 \%$ & $21.2 \%$ \\
8 & Kalman $\psi_{t}$ RW, with trend & $39.1 \%$ & $77.0 \%$ & $27.7 \%$ & $48.3 \%$ \\
9 & Kalman $\psi_{t}$ AR, no trend & $18.5 \%$ & $28.1 \%$ & $16.7 \%$ & $20.4 \%$ \\
10 & Kalman $\psi_{t}$ AR, with trend & $30.7 \%$ & $61.7 \%$ & $19.0 \%$ & $24.5 \%$ \\
11 & Kalman $\alpha_{t}$ and $\delta_{t}$ AR & - & - & $15.0 \%$ & $21.0 \%$ \\
12 & Kalman $\psi_{t}$ RW weekly data & $23.1 \%$ & $22.3 \%$ & - & - \\
13 & ESTAR $d=1$ & $18.5 \%$ & $22.2 \%$ & $19.9 \%$ & $21.1 \%$ \\
14 & Future Prices & $22.0 \%$ & - & $22.0 \%$ & - \\
15 & Survey Data & $14.0 \%$ & - & $14.0 \%$ & - \\
\hline \hline
\end{tabular}

Note: Root mean square error of one and two year ahead forecasts of a rolling sample with one year increment. One year includes 5 forecast points whereas two year includes 4 forecast points. Short sample refers to 1986.I-1999.II whereas long sample refers to 1974.I-1999.II. Model 11 has problems in converging in the small sample. 


\section{FIGURE 4.1}

Consumption, current account and financial assets with constant non-oil production

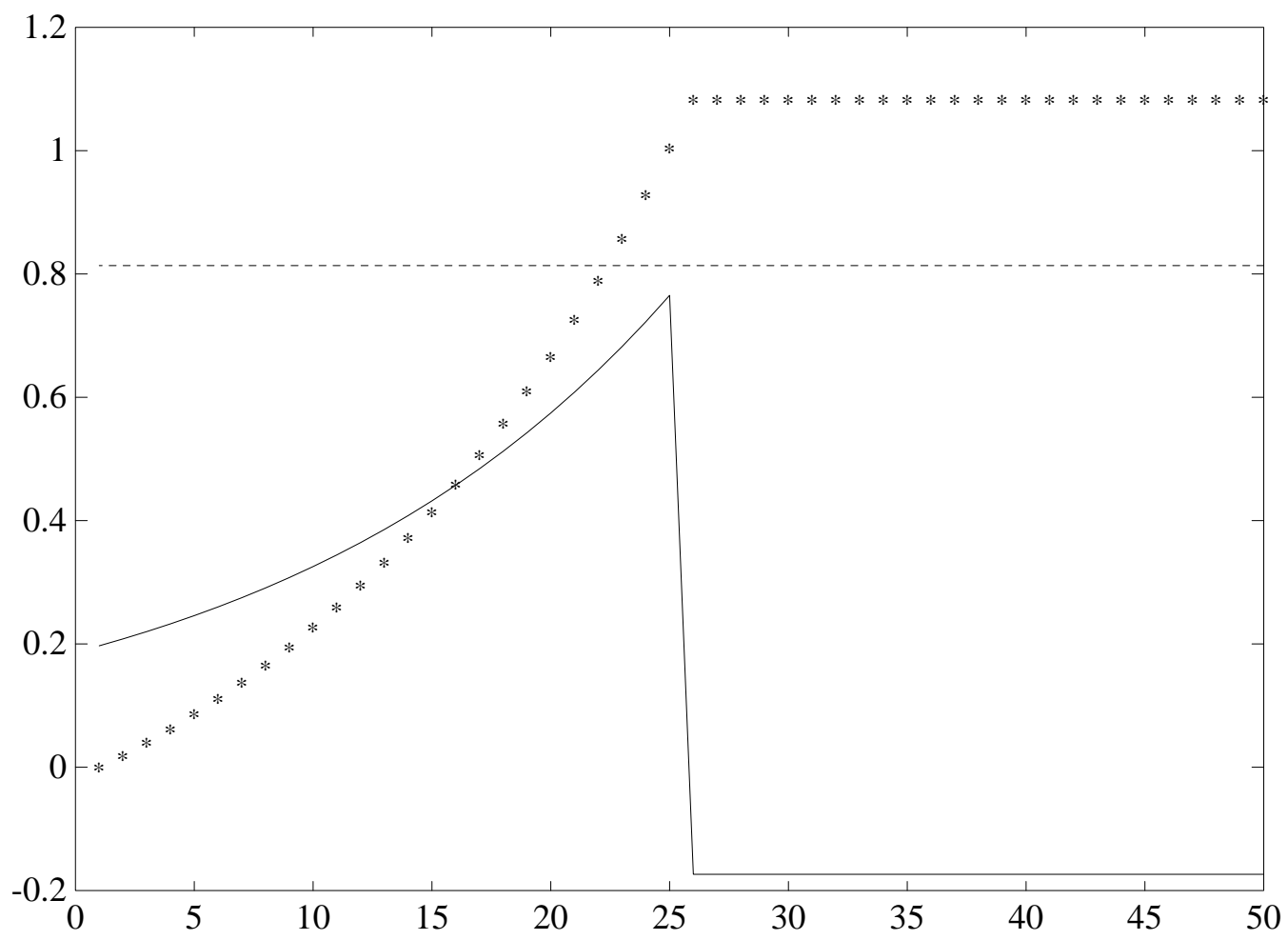

Note to Figure 4.1: The figure shows the optimal paths of normalized consumption (- - -), normalized financial assets $(* * *)$ and the current account as a fraction of GDP (-) under the assumptions of the benchmark model.

The following assumptions are made: no population growth $(n=0), R=1.06, \beta R=1$, no initial financial assets $\left(W_{1}=0\right)$, the optimal mix of the public and private goods requires that the former represent $20 \%$ of total consumption, initial oil production, which accrues to the government, accounts for $80 \%$ of GDP, while the remaining $20 \%$ is produced by the private sector. Oil production remains constant (in real terms) for 25 periods, moment at which oil reserves are exhausted. Production in the non-oil sector remains constant indefinitely. 
FIGURE 4.2

Consumption, current account, financial assets and taxes with increasing non-oil production

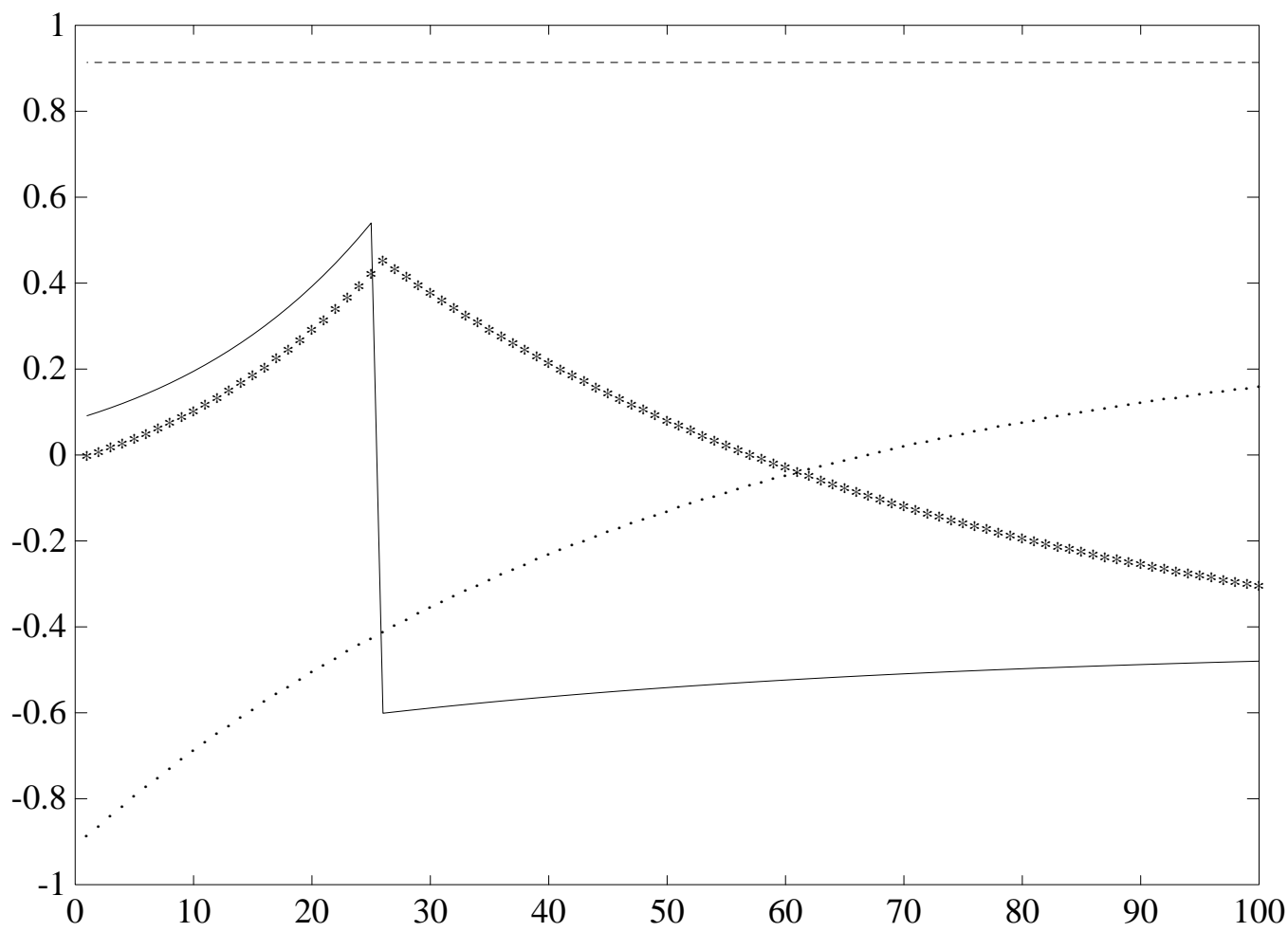

Note to Figure 4.2: The figure shows the optimal paths of normalized consumption (- - -), normalized financial assets as a fraction of non-oil GDP $(* * *)$, the current account as a fraction of GDP (-) and taxes as a fraction of non-oil GDP $(\cdots)$ under the assumptions of the benchmark model. The normalizing constants and the parameters are the same as in Figure 4.1, with the exception that non-oil production increases at an annual rate of $2 \%$. 
FIGURE 4.3

Optimal Consumption Path for Alternative Models with Increasing Non-Oil GDP

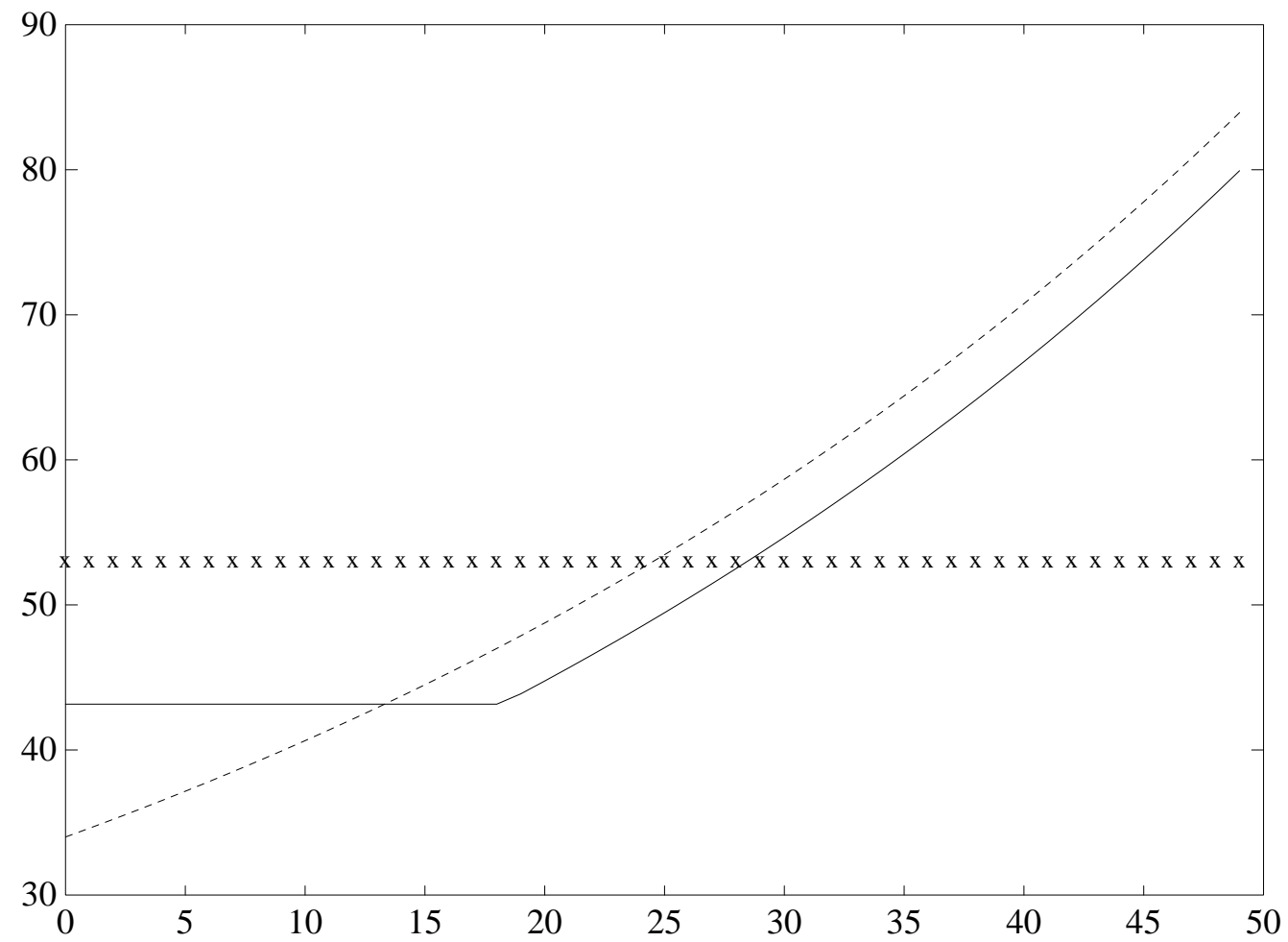

Note to Figure 4.3: The figure shows the optimal paths of consumption for the Benchmark Model (xxx), the Permanent Oil Income Model (- - ) and the Conditionally Normative Model $(-)$. Parameter values: no population growth; $R=1.04, \beta R=1$, initial oil wealth: 100; initial non-oil GDP: 30; non-oil GDP grows $2 \%$ per period for 50 periods and then remains constant forever. 
FIGURE 4.4

Optimal Consumption Path for Alternative Models with Decreasing Non-Oil GDP

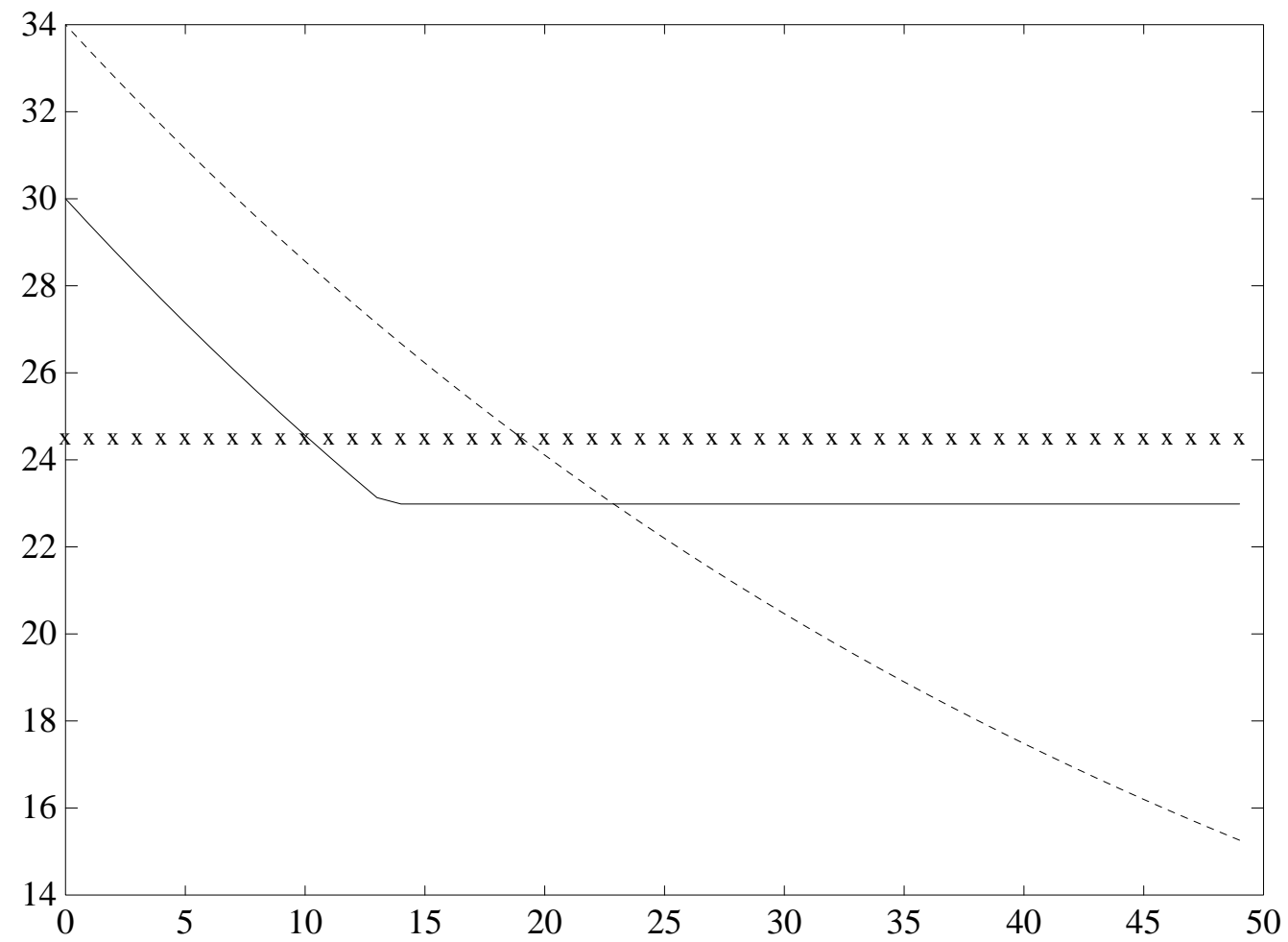

Note to Figure 4.4: The figure shows the optimal paths of consumption for the Benchmark Model (xxx), the Permanent Oil Income Model (- - ) and the Conditionally Normative Model (-). Parameter values: the only difference with Figure 4.3 is that non-oil GDP decreases $2 \%$ per period during the first 50 periods. 


\section{FIGURE 5.1}

Variance Ratio Test: $1957-1998$

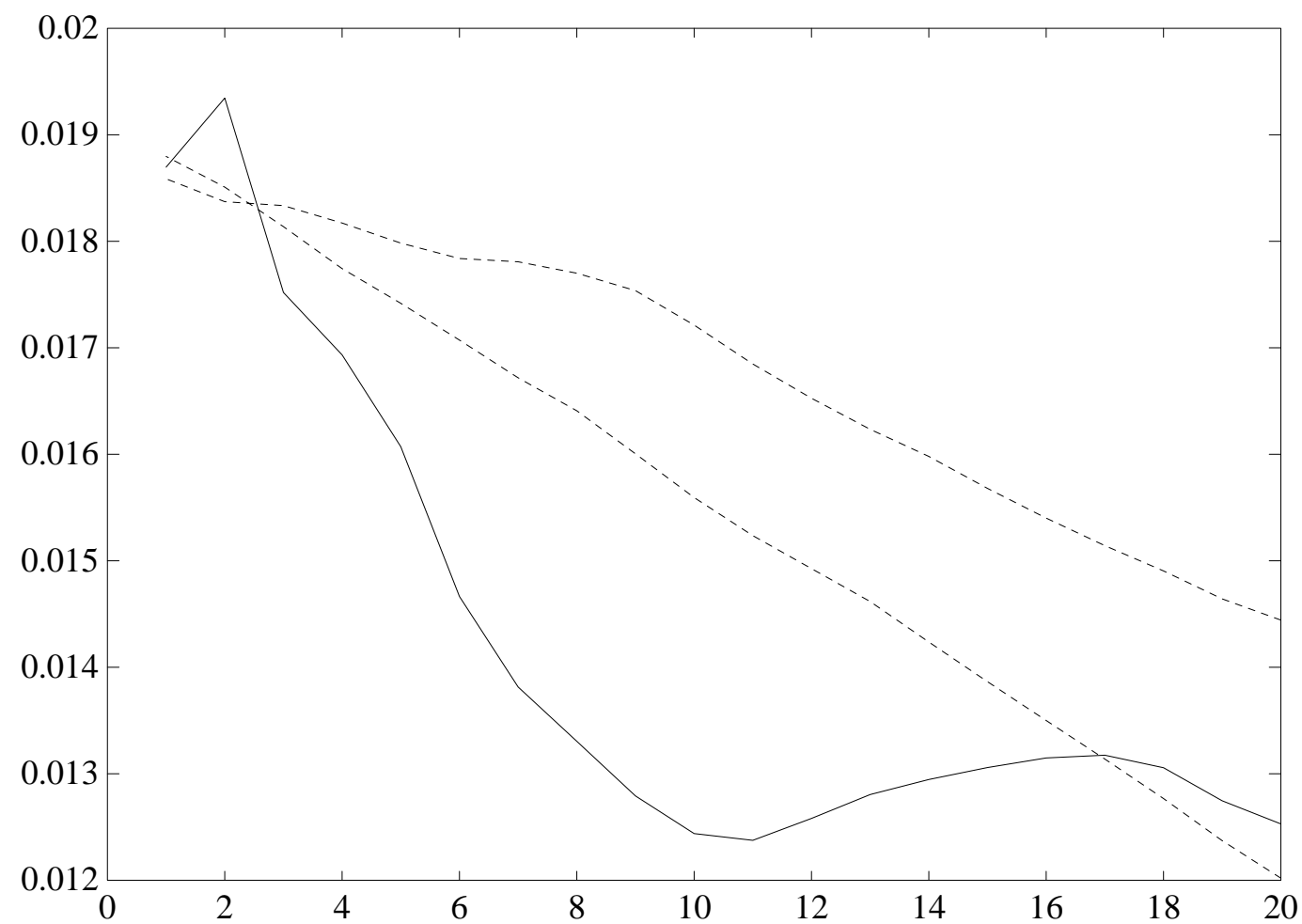

Note to Figure 5.1: The figure shows the results of the Variance Ratio tests for the sample 1957-1998 [solid line (-)]. The dashed lines (- - ) show the results of a Montecarlo exercise (with 1000 replications) assuming that the true process is a geometric random walk and a AR(1) with autoregressive coefficient equal to the sample estimate. 
FIGURE 5.2

Variance Ratio Test: 1974-1998

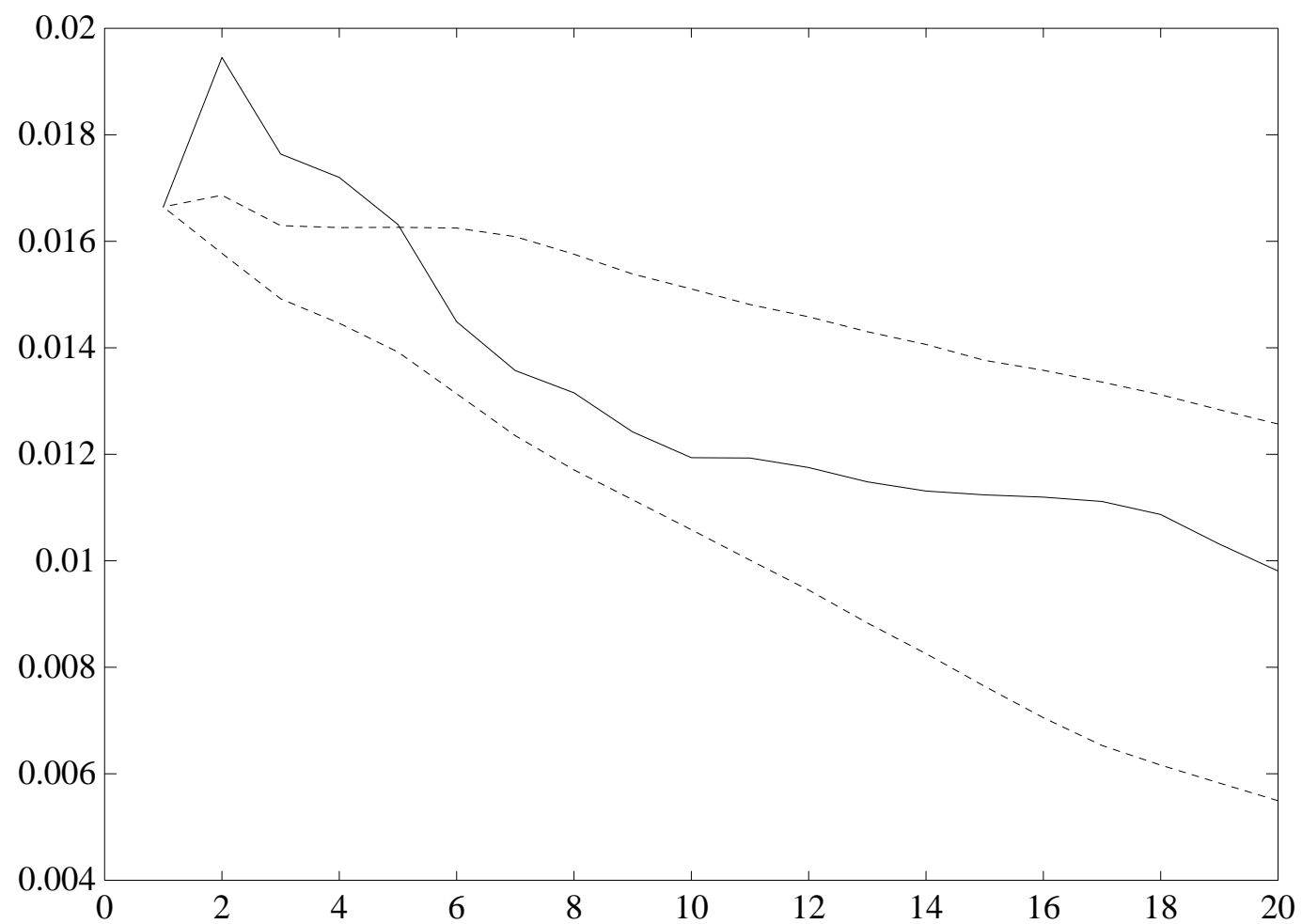

Note to Figure 5.2: The figure shows the results of the of the Variance Ratio tests for the sample 1974-1998 [solid line (-)]. The dash lines (- - ) show the results of a Montecarlo exercise (with 1000 replications) assuming that the true process is a geometric random walk and a AR(1) with autoregressive coefficient equal to the sample estimate. 
FIGURE 6.1

Correction Factors and Shock Persistence

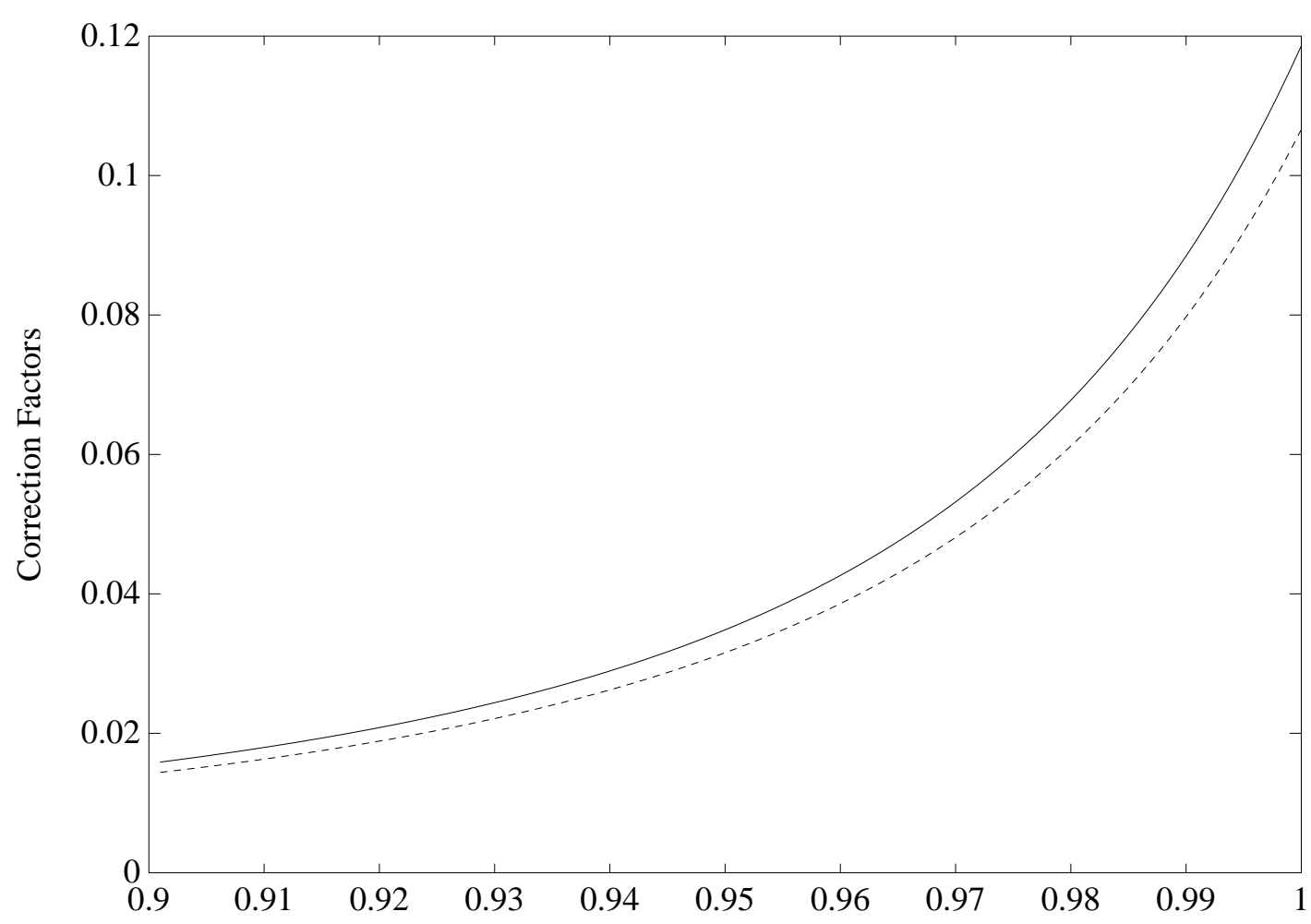

First order autocorrelation

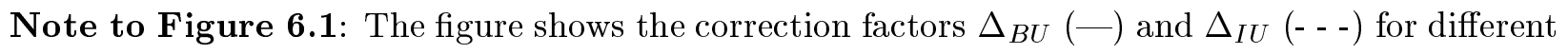
autoregressive coefficients $\psi$. The rest of the parameters correspond to those of example 6.1 . 
FIGURE 6.2

Correction Factors and Initial Financial Assets

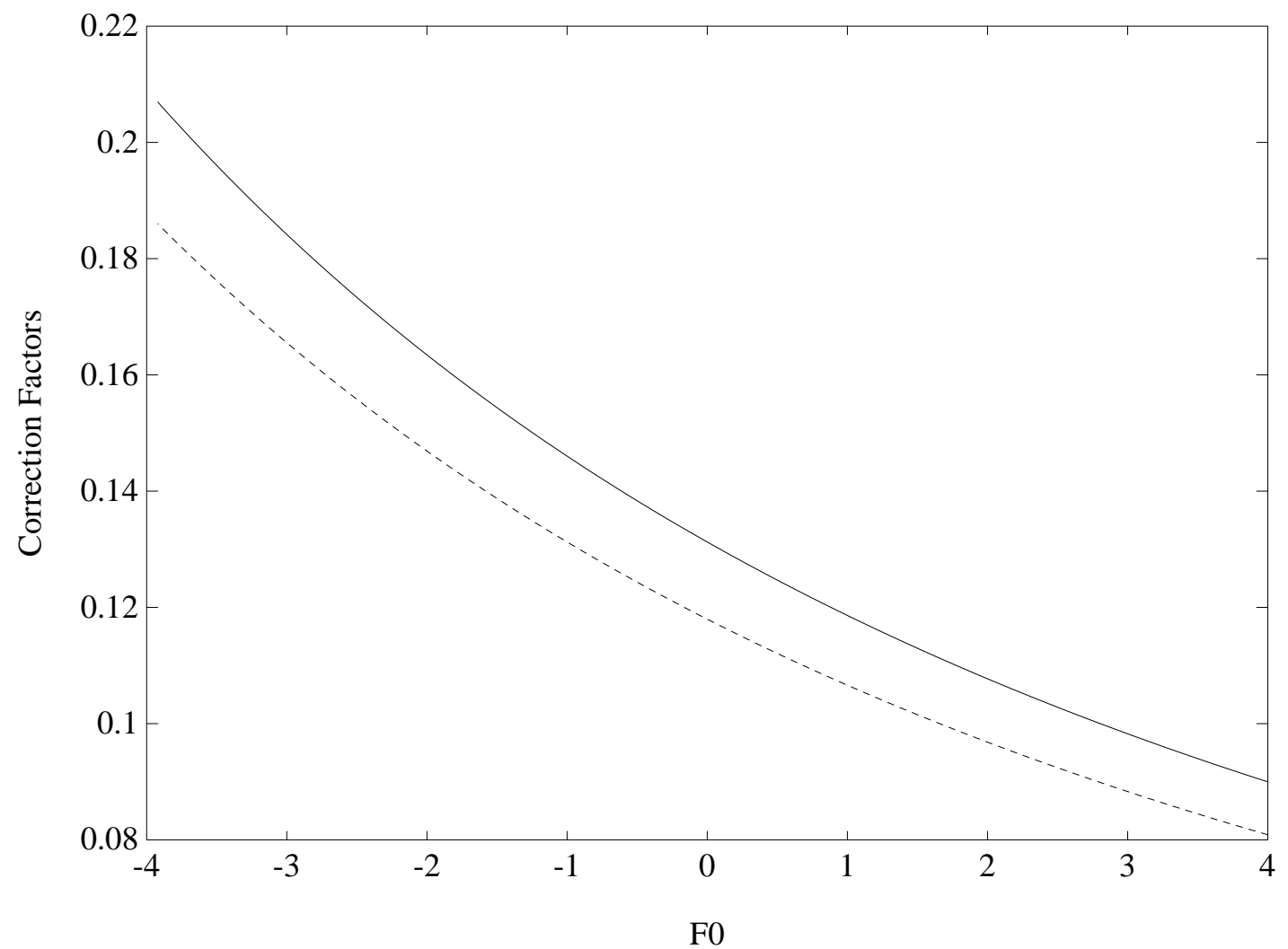

Note to Figure 6.2: The figure shows the correction factors $\Delta_{B U}(-)$ and $\Delta_{I U}(--)^{-)}$for different levels of initial financial assets (scaled by expected income in the first year). The rest of the parameters correspond to those of example 6.1. 


\section{FIGURE 6.3}

Correction Factors and Resource Duration

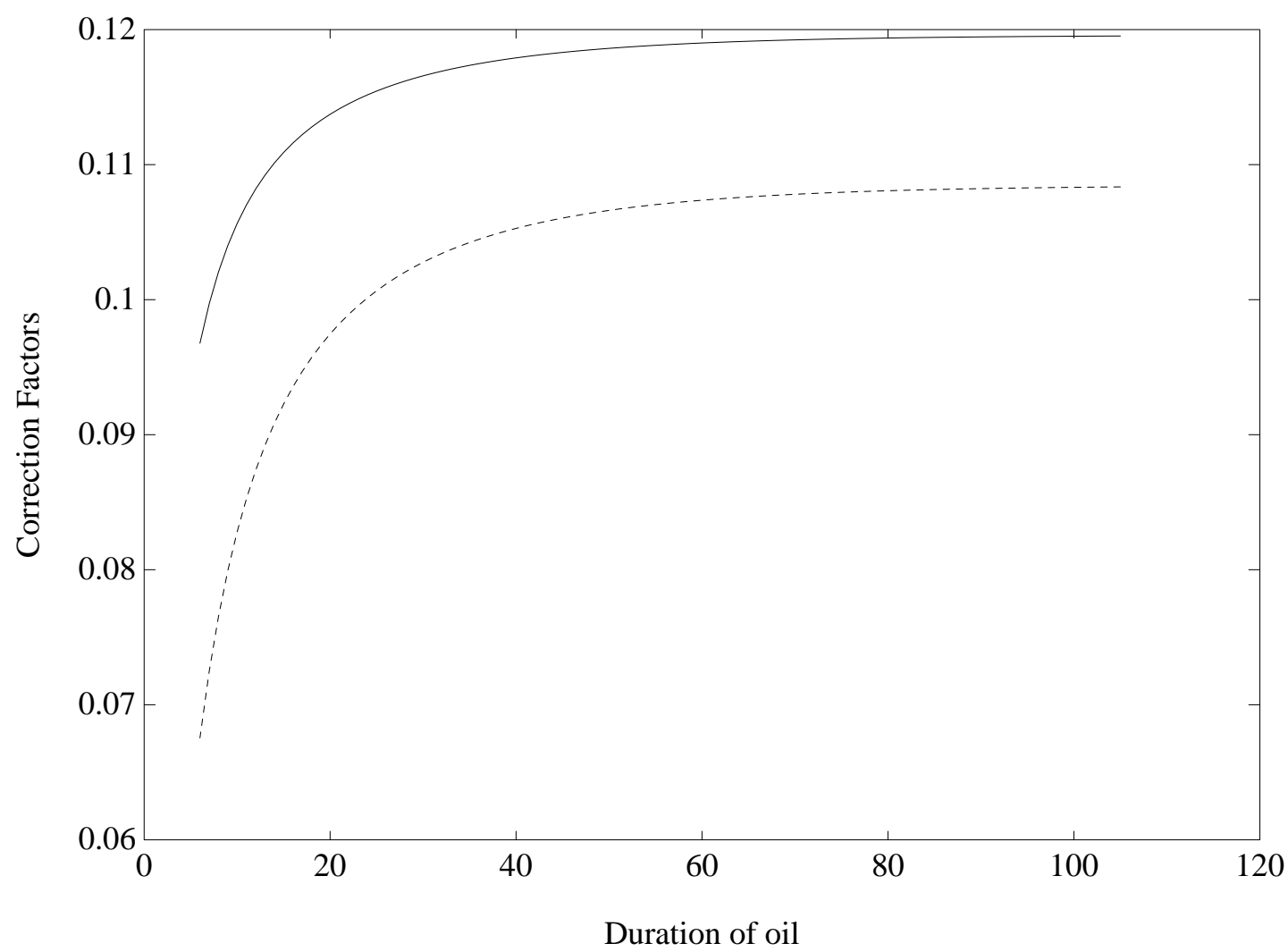

Note to Figure 6.3: The figure shows the correction factors $\Delta_{B U}(-)$ and $\Delta_{I U}$ (- - -) for different resource duration $T$. The rest of the parameters correspond to those of example 6.1. 
FIGURE 6.4

Correction Factors and Resource Duration

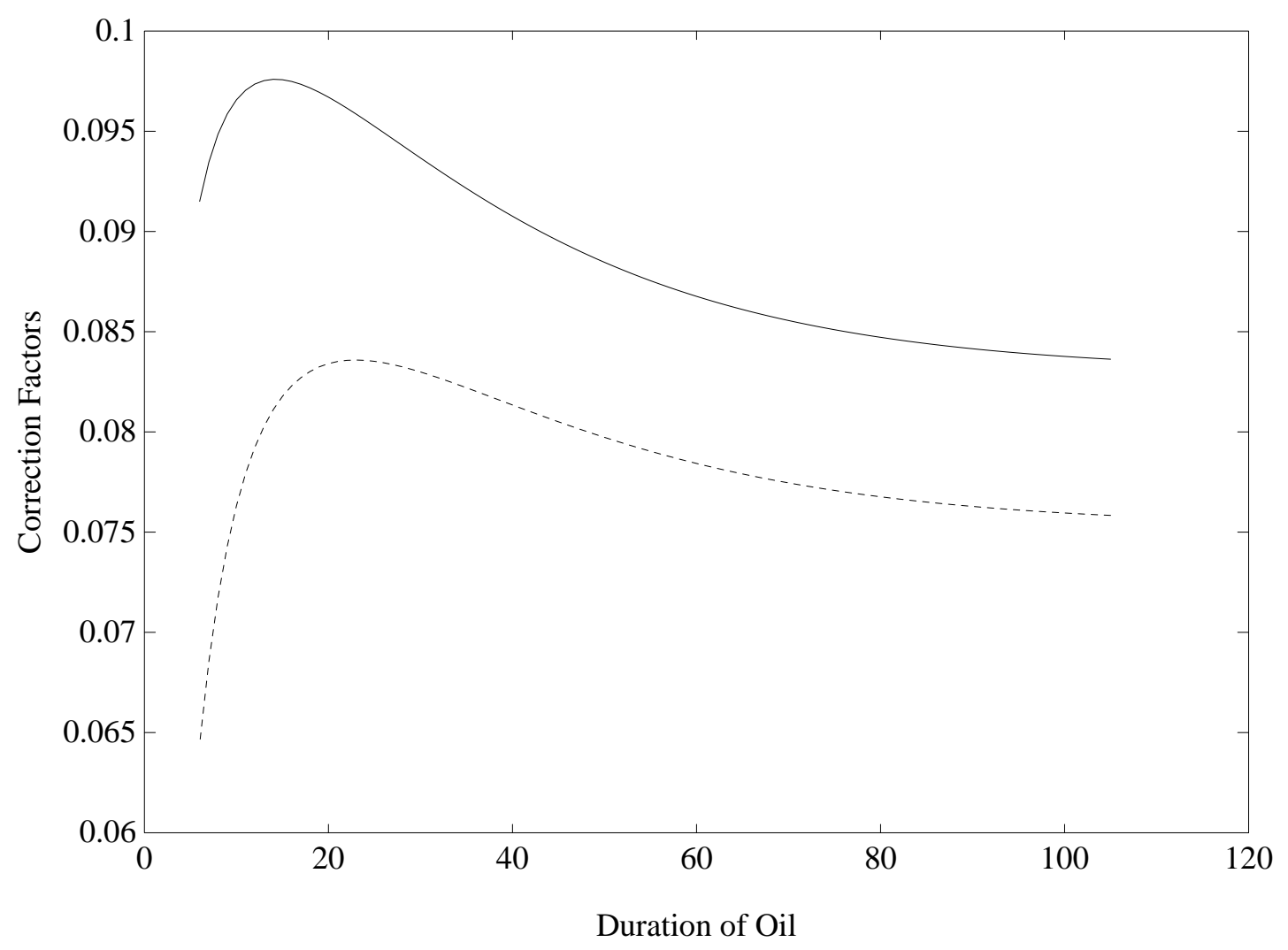

Note to Figure 6.4: The figure shows the correction factors $\Delta_{B U}(-)$ and $\Delta_{I U}(--)$ for different resource duration $T$ and $\psi=0.99$. The rest of the parameters correspond to those of example 6.1. 
FIGURE 6.5

Partial Adjustment Coefficient and Adjustment Cost

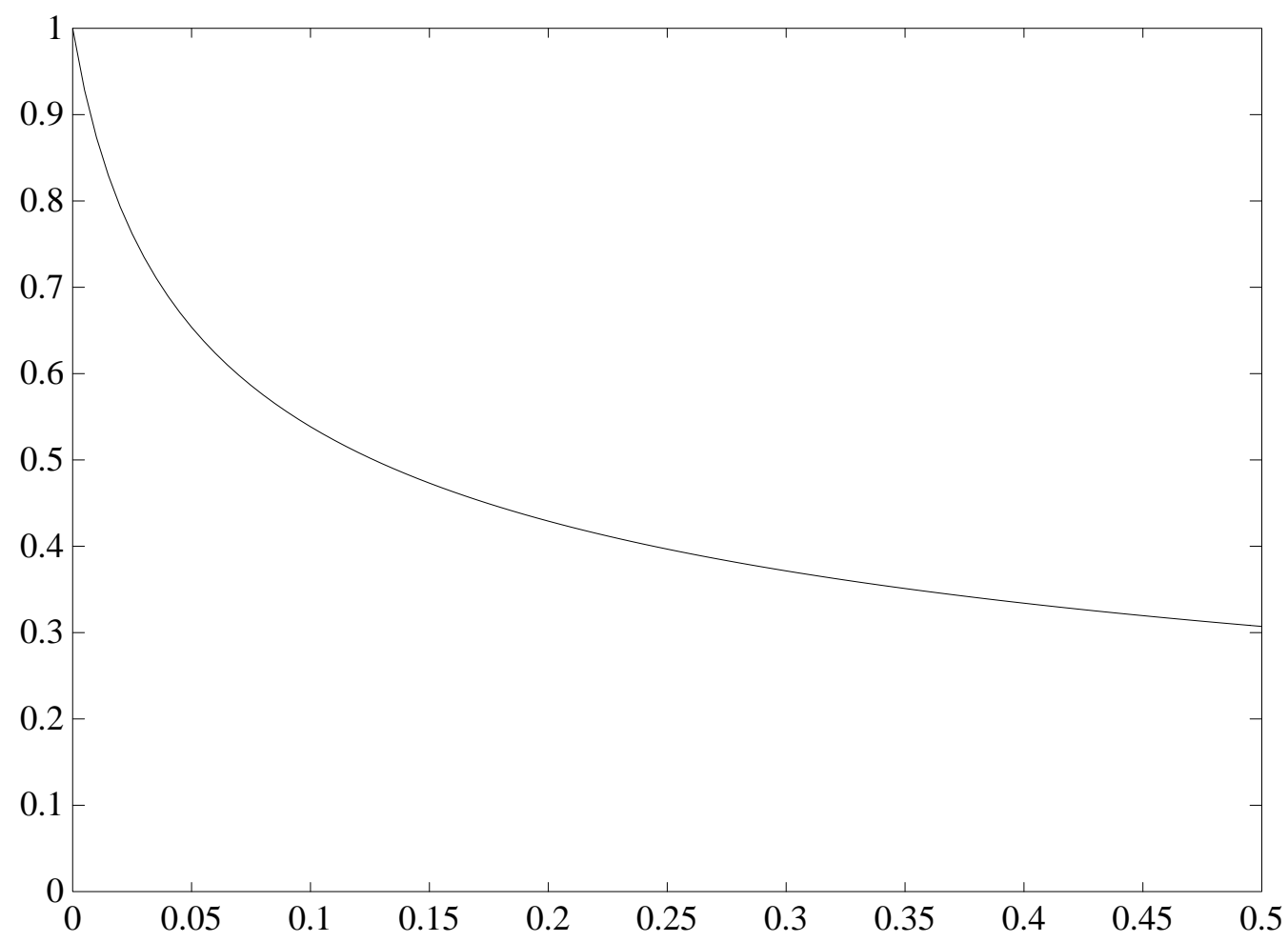

Note to Figure 6.5: The figure shows the partial adjustment coefficient for different values of the adjustment cost $\left(s_{n a}\right)$ for an adjustment $\left(s_{a}\right)$ of 0.20 The rest of the parameters correspond to those of example 6.5 . 
FIGURE 6.6

Partial Adjustment Coefficient and Risk Aversion

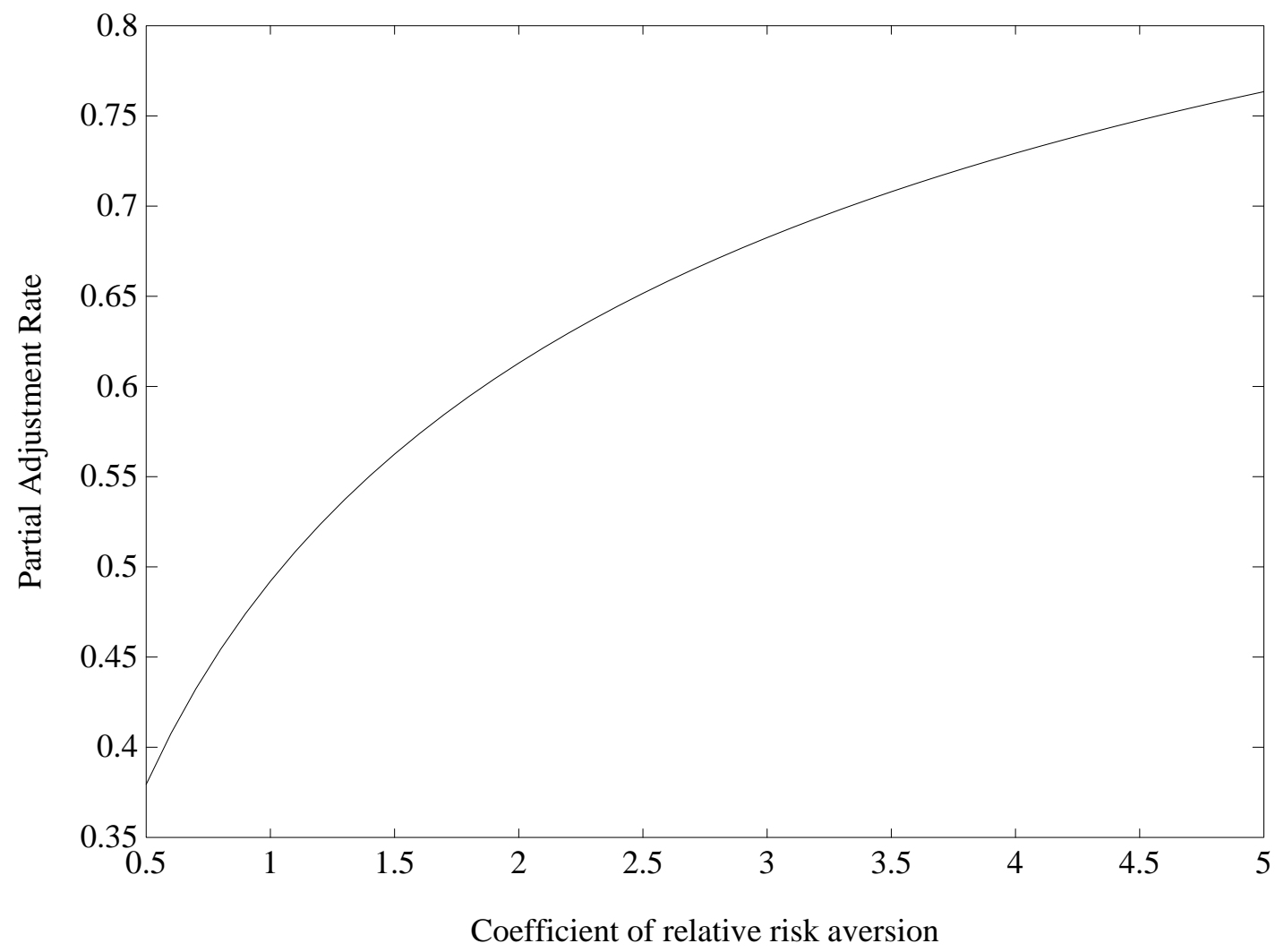

Note to Figure 6.6: The figure shows the partial adjustment coefficient for different values of the coefficient of relative risk aversion $(\rho)$ assuming $s_{n a}=0.04$ and $s_{a}=0.20$. The rest of the parameters correspond to those of example 6.5 . 